\title{
Metabolic potential and survival strategies of microbial communities across extreme temperature gradients on Deception Island volcano, Antarctica
}

7 'Departamento de Oceanografia Biológica, Instituto Oceanográfico, Universidade de São Paulo

8 (USP). Praça do Oceanográfico, 191. CEP: 05508-900 São Paulo, SP, Brazil.

9 Laboratório de Biologia Celular e Molecular, Centro de Energia Nuclear na Agricultura,

10 Universidade de São Paulo. Avenida Centenário 303, CEP 13416-00 Piracicaba, SP, Brazil.

$11{ }^{3}$ Department of Biology, Institute of Ecology and Evolution, University of Oregon, Eugene, OR,

12 United States

14 *Corresponding author:

15 Amanda Gonçalves Bendia

16 Address: Departamento de Oceanografia Biológica, Instituto Oceanográfico, Universidade de São

17 Paulo, São Paulo, Brazil. Praça do Oceanográfico, 191. CEP: 05508-900 São Paulo, SP, Brazil.

18 Email: amandagb@usp.br

19 Phone number: +55 (11) 3091-6557

21 Running Title: Community survival strategies on Deception Island 


\section{Abstract}

33 Active volcanoes in Antarctica, in contrast to the rest of the icy landscape, have remarkable

34 temperature and geochemical gradients that could select for a wide variety of microbial adaptive

35 mechanisms and metabolic pathways. Deception Island is a stratovolcano flooded by the sea,

36 resulting in contrasting ecosystems such as permanent glaciers $\left(<0{ }^{\circ} \mathrm{C}\right)$ and active fumaroles (up

37 to $\left.100{ }^{\circ} \mathrm{C}\right)$. Steep gradients in temperature, salinity and geochemistry over very short distances

38 have been reported for Deception Island, and have been shown to effect microbial community

39 structure and diversity. However, little is known regarding how these gradients affect ecosystem

40 functioning, for example due to inhibition of key metabolic enzymes or pathways. In this study,

41 we used shotgun metagenomics and metagenome-assembled genomes to explore how microbial

42 functional diversity is shaped by extreme geochemical, salinity and temperature gradients in

43 fumarole and glacier sediments. We observed that microbial communities from a $98{ }^{\circ} \mathrm{C}$ fumarole

44 harbor specific hyperthermophilic molecular strategies, as well as reductive and autotrophic

45 pathways, while those from $<80{ }^{\circ} \mathrm{C}$ fumaroles possess more diverse metabolic and survival

46 strategies capable of responding to fluctuating redox and temperature conditions. In contrast,

47 glacier communities showed less diverse metabolic potentials, comprising mainly heterotrophic

48 and carbon pathways. Through the reconstruction of genomes, we were able to clarify putative

49 novel lifestyles of underrepresented taxonomic groups, especially those related to Nanoarchaeota

50 and thermophilic ammonia-oxidizing archaeal lineages. Our results enhance understanding of the

51 metabolic and survival capabilities of different extremophilic lineages of Bacteria and Archaea.

53 Key words: Deception Island, Antarctica, Microbial ecology, Microbial processes, Metagenome-

54 assembled genomes, Extremophiles 


\section{Introduction}

56 The study of life in extreme environments has long fascinated biologists. Understanding how life

57 persists at environmental extremes provides insight into how living systems function, as well as

58 providing a unique window into the evolutionary history of life itself (Merino et al., 2019). The

59 Deception Island volcano contains a unique combination of extreme temperatures and geochemical

60 energy sources that together have the potential for selecting a wide variety of microbial adaptive

61 mechanisms and metabolic pathways. Deception Island is located in the South Shetland Islands at

62 the spreading center of the Bransfield Strait marginal basin, which harbors contrasting ecosystems

63 of permanent glaciers and active fumaroles with continuous emissions of gases, mostly carbon

64 dioxide and hydrogen sulfide (Somoza et al., 2004). This combination of glaciers and fumaroles

65 is produced by the interaction between the cryosphere and water mass contact with hot ascending

66 magmas (Geyer et al., 2019). Unlike Antarctic continental volcanoes, Deception Island fumaroles

67 reach up to $100{ }^{\circ} \mathrm{C}$ and have direct marine influence, creating a remarkable combination of thermal,

68 geochemical and salinity gradients (Bartolini et al., 2014; Herbold et al., 2014; Muñoz-Martín et

69 al., 2005).

70

71 While early research carried out on Deception focused primarily on obtaining bacterial isolates

72 from hot or cold ecosystems (e.g. Carrión et al., 2011; Llarch et al., 1997; Stanley et al., 1967), a

73 more recent study was able to recover both psychrophilic and thermophilic isolates among the

74 steep temperature gradients (Bendia et al., 2018a). Previous molecular studies described microbial

75 diversity on Deception fumaroles using DGGE (Amenábar et al., 2013; Muñoz et al., 2011) and

76 shotgun metagenomics to characterize the resistome profiles in cold sediments from Whalers Bay 
77 (Centurion et al., 2019). These previous studies were limited with respect to sampling depth and

78 extent since only fumaroles or cold sediments were analyzed.

80 Two previous studies have focused on understanding the effect of Deception temperature gradients

81 on microbial communities. The first, performed by our group, focused on determining taxonomic

82 diversity through 16S rRNA gene sequencing (Bendia et al., 2018b), and a second study applied

83 the Life Detector Chip (LDChip) to describe general functions of communities from Cerro Caliente

84 (Lezcano et al., 2019). Our previous study showed that the steep gradients on Deception were able

85 to select a unique combination of taxonomic groups found in deep and shallow hydrothermal vents

86 (including hyperthermophilic Archaea, such as Pyrodictium spp.), geothermal systems and those

87 typical from polar ecosystems (Bendia et al., 2018b). Also we reported that the bacterial

88 community structure on Deception Island is strongly niche driven by a variety of environmental

89 parameters (temperature, $\mathrm{pH}$, salinity and volcanic geochemicals, such as sulfate), while archaeal

90 diversity is mainly shaped by temperature (Bendia et al., 2018b). These previous studies, however,

91 did not address the linkages between microbial structure and their adaptive and metabolic

92 strategies over the particular environmental gradients found on Deception Island.

94 Although several studies have demonstrated that temperature is a primary driver of microbial

95 taxonomic diversity in different geothermal and hydrothermal ecosystems (e.g. Antranikian et al.,

96 2017; Price and Giovannelli, 2017; Sharp et al., 2014; Ward et al., 2017), it is still unclear to what

97 extent temperature affects the functional processes of a microbial community, such as their

98 adaptive mechanisms and metabolic pathways. The majority of these previous studies have

99 focused on nonpolar thermal ecosystems, where the temperature range is narrower than in polar 
100 volcanoes; the exception is a study of deep-sea hydrothermal vents, in which the contrasting

101 temperatures are created by the contact of heat with the surrounding cold seawater (with

102 temperatures $0-4{ }^{\circ} \mathrm{C}$ ). Indeed, the Deception communities from fumaroles have similar members

103 (Bendia et al., 2018b) to those found in deep-sea hydrothermal vents (e.g. Dick, 2019; Nakagawa

104 et al., 2006; Takai et al., 2001), which suggests that, regarding differences in pressure (and other

105 environmental effects), the wide temperature range typical of polar volcanoes and deep-sea

106 hydrothermal vents can act as a strong selective pressure that favors (hyper)thermophilic

107 specialists capable of thriving in high temperatures but that can also tolerate the cold surroundings.

108

109 Furthermore, there is controversy about the impact of extreme environments on microbe-microbe

110 interactions. Although some studies have reported a decrease in the frequency of microbe-microbe

111 interactions inferred from co-occurrence patterns (Cole et al., 2013; Merino et al., 2019; Sharp et

112 al., 2014), others have observed the opposite trend (Lin et al., 2016; Mandakovic et al., 2018). The

113 analysis of co-occurrence patterns is useful for examining the nature of the ecological

114 rearrangements that take place in a microbial community facing contrasting environments (Freilich

115 et al., 2010; Mandakovic et al., 2018).

117 In the current study, we assessed the microbial functional profile in fumarole and glacier sediments

118 from two geothermal sites on the Deception Island volcano, Antarctica. For this, we performed

119 shotgun metagenomics to unveil functional diversity and reconstructed genomes to reveal the

120 microbes` putative lifestyles and survival capabilities, combining the genomic information with

121 community functional profiles. Here, we hypothesize that (i) similar to what has been reported for

122 community diversity, survival and metabolic strategies are also influenced by the combination of 
123 geochemical, salinity and extreme temperature gradients; (ii) these communities follow the

124 redundancy of metabolic potential that was reported for deep-sea hydrothermal vent communities;

125 and (iii) microbe-microbe interactions decrease with increasing temperature. This study adds

126 important information regarding the ecological processes of microbial communities inhabiting a

127 steep gradient of temperature, and addresses central questions regarding the functional adaptability

128 of extremophiles in polar regions.

\section{$131 \quad$ Materials and methods}

\section{Study site and sampling strategy}

133 Deception Island $\left(62^{\circ} 58^{\prime} \mathrm{S}, 60^{\circ} 39^{\prime} \mathrm{W}\right)$ is a complex stratovolcano located in the South Shetland

134 Islands, Bransfield Strait, near the Antarctic Peninsula. A past eruption occurring approximately

13510,000 years ago collapsed the central part of the island giving rise to a flooded caldera called Port

136 Foster Bay, $9 \mathrm{~km}$ in diameter (Baker et al., 1975). Fumaroles are found mainly at Fumarole Bay

137 (FB), Whalers Bay (WB), and Pendulum Cove (Fermani et al., 2007; Geyer et al., 2019), and they

138 are distributed mostly in submerged and partially submerged regions (intertidal zones), with

139 temperatures varying from $40-60^{\circ} \mathrm{C}$ in $\mathrm{WB}$ and $80-100^{\circ} \mathrm{C}$ in FB (Rey et al., 1995; Somoza et al.,

140 2004). Carbon dioxide and hydrogen sulfide gases are emitted by fumaroles and are oxidized to

141 products such as sulfite and sulfate (Somoza et al., 2004; Zhang and Millero, 1993).

143 Sampling was performed during the XXXII Brazilian Antarctic Expedition (December 2013 to

144 January 2014), with logistical support from the polar vessel NPo. Almirante Maximiano. We

145 collected surface sediment samples $(c a .5 \mathrm{~cm})$ in fumaroles and glaciers at geothermally active 


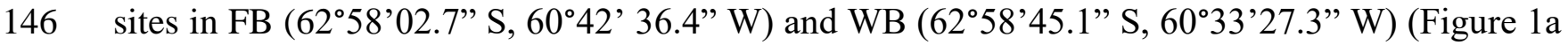

147 and $1 \mathrm{~b}$ ), with temperatures between 0 and $98{ }^{\circ} \mathrm{C}$. At each site, we obtained samples from three

148 different points within the temperature gradient, and triplicates were performed for each collected

149 point, totaling 18 sediment samples. Points A and B were defined as samples collected in

150 fumaroles, while point $\mathrm{C}$ samples were collected from the glacier, few $\mathrm{cm}$ below the glacier's edge

151 (Figure 1c and 1d). The point FBA was the hottest fumarole, measuring $98{ }^{\circ} \mathrm{C}$ at the sediment

152 surface (ca. $20 \mathrm{~cm}$ ). Distances between fumaroles and glaciers at each site were approximately 15

$153 \mathrm{~m}$, and the WB and FB transects were approximately $10 \mathrm{~km}$ apart. All fumaroles were in the

154 intertidal zone, except for point B from $\mathrm{FB}$, which was in the subtidal zone (submerged at $50 \mathrm{~cm}$

155 depth in the water column). Samples were stored at $-20{ }^{\circ} \mathrm{C}$ until arrival at the University of São

156 Paulo, Brazil in April 2014.

158 DNA Extraction and metagenomic sequencing

159 To compare our results with the study performed by Bendia et al. (2018b), we used the same

160 dataset and DNA extractions as a template for the metagenomics. Due to low DNA mass even

161 after several concentration efforts, extracted DNA was subjected to multiple displacement

162 amplification (MDA) using the illustra GenomiPhi V2 DNA amplification kit (GE Healthcare,

163 Piscataway, NJ, USA), following the manufacturer's instructions. Three amplification reactions

164 per sample were pooled to obtain sufficient DNA for sequencing. DNA was then purified using

165 AMPure XP beads kit (Beckman Coulter) following the manufacturer's instructions. Library

166 constructions and shotgun metagenomic sequencing were conducted at "Laboratório Central de

167 Tecnologias de Alto Desempenho em Ciências da Vida" (LaCTAD), Universidade Estadual de 
168 Campinas State (UNICAMP), on the Illumina Hiseq 2000 platform using 2x100 bp paired-end 169 system.

171 Physical-chemical parameters

172 To correlate biological and environmental data, we used the physical-chemical parameters for 173 sediments measured by Bendia et al. (2018b), which included granulometry, electrical 174 conductivity, humidity, micronutrients ( $\mathrm{B}, \mathrm{Cu}, \mathrm{Fe}, \mathrm{Mn}$, and $\mathrm{Zn}$ ), organic matter, organic carbon, $175 \mathrm{pH}, \mathrm{P}, \mathrm{Si}, \mathrm{Na}, \mathrm{K}, \mathrm{Ca}, \mathrm{Mg}, \mathrm{Al}$, total nitrogen, nitrate, ammonia, and sulfate.

\section{Taxonomic and functional inference of metagenomic reads}

178 Reads were quality trimmed using Sickle (Joshi and Fass, 2011) with phred >30 and then uploaded

180 through subsystem and best hit classifications using the SEED subsystem, M5NR (non-redundant 181 protein database) and KEGG, available in MG-RAST (Aziz et al., 2008; Kanehisa and Goto, 2000;

182 Keegan et al., 2016; Wilke et al., 2012), with the following parameters: $1 \times 10^{-5}$ e-value, minimum 18350 bp alignment, and 60\% identity. Data generated by MG-RAST were statistically analyzed using

184 Statistical Analysis of Metagenomic Profiles (STAMP) software (Parks et al., 2014) and R

185 software (R Development Core Team), using the packages vegan (Oksanen, 2007) and ggplot

186 (Wickham, 2011). The $p$ values were calculated using Fisher's exact two-sided test and the 187 confidence intervals were calculated using the method of Newcombe-Wilson. Statistical 188 comparisons were performed by grouping the samples according to environmental temperatures: 189 glaciers, fumaroles up to $80{ }^{\circ} \mathrm{C}$ and fumarole at $98{ }^{\circ} \mathrm{C}$. Principal component analysis (PCA) 190 ordination was performed by using level 3 functions of SEED subsystems and then visualized in 
191 STAMP software. Values were normalized to relative abundance for comparison of taxonomic

192 composition across samples. In addition, Spearman correlations were performed to determine

193 relationships between taxonomic and functional profiles and the environmental parameters.

194 Genetic data are available in MG-RAST under the project ID mgp15628. MG-RAST IDs for each

195 sample are described in Supplementary Table 2.

197 To investigate the complexity of community interactions at each sampling site, we used co-

198 occurrence network analysis. For this, non-random co-occurrence analyses were performed using

199 the Python module 'SparCC' (Friedman and Alm, 2012). A table of frequency of hits affiliated to

200 the genus level was used for analysis. For each network, we considered only strong (SparCC $>0.9$

201 or $<-0.9)$ and highly significant $(p<0.01)$ correlations between microbial taxa. The nodes in the

202 reconstructed network represent taxa at the genus level, whereas the edges represent significantly

203 positive or negative correlation between nodes. The analysis of network complexity was based on

204 a set of measures, such as the number of nodes and edges, modularity, the number of communities,

205 average node connectivity, average path length, diameter, and cumulative degree distribution

206 (Newman, 2003). Network visualization and property measurements were calculated with the

207 software Gephi (Bastian et al., 2009).

\section{Metagenomic assembly and genome reconstruction}

211 We used two different strategies for metagenomic assembly and genomic binning of the eighteen

212 metagenomic datasets from Deception Island volcano. First, reads were assembled using IDBA-

213 ud (Peng et al., 2012) (-mink 50, -maxk 92, -tep 4, -min_contig 1000) and then genomic binning

214 was performed through MaxBin 2.0 (Wu et al., 2016). Contigs were annotated using the Integrated 
215 Microbial Genomes \& Microbiomes (IMG/M) system (Markowitz et al., 2009) and archived on

216 the JGI/IMG server under Project ID Gs0141992. IMG accession numbers for each sample are

217 described in Supplementary Table 2.

218

219 Furthermore, reads were co-assembled using MEGAHIT v. 1.0.2. (Li et al., 2015), discarding 220 contigs smaller than $1000 \mathrm{bp}$. Then contigs were binned using anvi'o v. 5 following the workflow

221 described by Eren et al. (2015). Reads for each metagenome were mapped to the co-assembly 222 using bowtie2 with default parameters (Langmead and Salzberg, 2012). A contig database was 223 generated using the 'anvi-gen-contigs-database'. Prodigal (Hyatt et al., 2010) was used to predict

224 open reading frames (ORFs). Single-copy bacterial and archaeal genes were identified using 225 HMMER v. 3.1 b2 (Finn et al., 2011). The program 'anvi-run-ncbi-cogs' was used to annotate 226 genes with functions by searching for them against the December 2014 release of the Clusters of 227 Orthologous Groups (COGs) database (Galperin et al., 2015) using blastp v2.10.0+ (Altschul et 228 al., 1990). Predicted protein sequences were functionally and taxonomically annotated against 229 KEGG with GhostKOALA (genus_prokaryotes) (Kanehisa et al., 2016). Individual BAM files 230 were profiled using the program 'anvi-profile' with a minimum contig length of $4 \mathrm{kbp}$. Genome 231 binning was performed using CONCOCT (Alneberg et al., 2013) through the 'anvi-merge' 232 program with default parameters. We used 'anvi-interactive' to visualize the merged data and 233 identify genome bins. Bins were then manually refined using 'anvi-refine', and completeness and 234 contamination were estimated using 'anvi-summarize'.

236 Bins generated by the assembly and co-assembly approaches were quality checked through 237 CheckM v. 1.0.7 (Parks et al., 2015), which is based on the representation of lineage-specific 
marker gene sets. Bins were taxonomically classified based on genome phylogeny using GTDB-

239 Tk (Chaumeil et al., 2020).

241 Taxonomic and functional annotation of metagenome-assembled genomes (MAGs)

242 Bins were defined as a high-quality draft (>90\% complete, $<5 \%$ contamination), medium-quality

243 draft $(>50 \%$ complete, $<10 \%$ contamination) or low-quality draft $(<50 \%$ complete, $<10 \%$

244 contamination) metagenome assembled-genome (MAG), according to genome quality standards

245 suggested by Bowers et al. (2017). We selected 11 MAGs based on their medium or high-quality

246 and taxonomy, preferably selecting groups related to extremophiles or associated to sulfur and

247 nitrogen metabolisms. Annotation of all predicted ORFs in MAGs was performed using prokka

248 v.14.5 (Seemann, 2014). Further, proteins were compared to sequences in the KEGG Database

249 through GhostKOALA (genus_prokaryotes) (Kanehisa et al., 2016) and in the SEED Subsystem

250 through RASTtk (Brettin et al., 2015). Phenotypes were predicted using the PICA framework

251 (Feldbauer et al., 2015) and PhenDB (https://phendb.csb.univie.ac.at/).

\section{Results}

254 To investigate links between metabolic potential and genes associated with survival strategies

255 across extreme temperature and geochemical gradients of the Deception Island volcano, we 256 analyzed the metagenomes of a total of eighteen samples, comprising fumaroles with temperatures

257 of $98^{\circ} \mathrm{C}, 80^{\circ} \mathrm{C}, 50^{\circ} \mathrm{C}$, and $10^{\circ} \mathrm{C}$, and glaciers with temperatures around $0{ }^{\circ} \mathrm{C}$. Shotgun sequencing 258 of community genomic DNA on 3 lanes of Illumina HiSeq2000 produced a total of 567,410,264

259 paired-end reads, within which 475,895,996 were filtered by quality (Q>30) for further analyses.

260 A total of $162,755,88$ reads were taxonomically annotated as Bacteria, 3,680,020 as Archaea, 

predicted in reads were 296,818,692 (62.3\%). Relative abundances of the detected genes were

263 used to compare the metabolic potential and genes related to survival strategies under

264 environmental extremes among fumaroles and glaciers samples.

De novo assemblies of the quality-filtered reads generated a total of 543,945 contigs. The

267 prediction of ORFs resulted in 1,396,820 putative genes, 353,731 assigned within Bacteria, 12,034

268 within Archaea, and 1,557 and 1,534 within Eukarya and viruses, respectively. We used different

269 databases for assembly annotation through JGI/IMG that resulted in 487 putative 16S rRNA genes,

270842,798 genes based on the COG database and 304,173 genes based on KEGG (Supplementary

271 Table 2).

272

\section{Taxonomic profile of microbial communities on the Deception Island volcano}

274 Through the annotation of reads, we observed that the taxonomic composition in the $98{ }^{\circ} \mathrm{C}$

275 fumarole was distinct in comparison with other fumaroles and glaciers. Archaea were dominant in

276 samples from the $98{ }^{\circ} \mathrm{C}$ fumarole (relative abundance between 31.5 and $87.3 \%$ ), with the most

277 abundant archaeal phyla classified as Crenarchaeota (23.8-79.3\%), followed by Euryarchaeota

278 (2.5-7.5\%) and Korarchaeota (0.1-0.4\%). Firmicutes (3.1-22.4\%), Bacteroidetes (0.6-15.3\%),

279 Aquificae (0.3-4.6\%), and Thermotogae (0.3-1.0\%) were also detected in minor proportions in the

$28098{ }^{\circ} \mathrm{C}$ fumarole. Looking at the class level, Thermoprotei, Thermococci, Methanococci,

281 Archaeoglobi, Methanobacteria, Methanopyri, and Methanomicrobia represented the most

282 abundant archaeal classes $(>0.1 \%)$ in the $98{ }^{\circ} \mathrm{C}$ site, and Bacilli, Gammaproteobacteria, 
283 Betaproteobacteria, Fusobacteria, Flavobacteria, Aquificae (order Aquificales) and Thermotogae

284 (order Thermotogales) were the dominant classes within Bacteria (Figure 2a).

286 Archaea were less dominant in the other samples, with a relative abundance of $0.7-2 \%$ in fumaroles

$287<80{ }^{\circ} \mathrm{C}$ and $0.4-0.6 \%$ in glaciers. Although some dominant phyla were common between $<80{ }^{\circ} \mathrm{C}$

288 fumaroles and glaciers (e.g. Bacteroidetes, Proteobacteria, and Firmicutes), less dominant phyla

289 were uniquely distributed according to temperature. For example, Thaumarchaeota was

290 predominantly found in $<80{ }^{\circ} \mathrm{C}$ fumaroles $(0.8-1 \%$ for Whalers Bay and $0.2-0.3 \%$ in Fumarole

291 Bay). Verrucomicrobia and Acidobacteria were only detected in glaciers (1.2-3.1\% and 1-1.6\%,

292 respectively) (Figure 2a). The main classes affiliated within the Bacteroidetes phylum were

293 Cytophagia, Flavobacteria and Sphingobacteria, whereas Gamma- and Alphaproteobacteria were

294 the most represented classes within Proteobacteria, followed by Beta-, Delta- and Epsilonbacteria

295 (Figure 2b). Solibacteres was the abundant class within Acidobacteria, and Verrucumicrobiaea

296 within Verrucomicrobia. Thaumarchaeota assignments were not classified at the class level using

297 reads annotation in MG-RAST. The taxonomic annotation of contigs through the IMG/M system

298 showed similar patterns when compared to reads annotation (Supplementary Figure 1).

300 We then used co-occurrence network analysis to explore the complexity of interactions within the

301 microbial communities in each treatment (Figure 2c). For this, we calculated SparCC correlations

302 between microbial taxa at the genus level based on metagenome reads annotated in MG-RAST. In

303 general, the complexity of the community increased with the temperature. We also noted that

304 communities of Fumarole Bay were more complex than Whalers Bay. The FBA $\left(98^{\circ} \mathrm{C}\right)$ site

305 showed the highest level of complexity and a modular structure, whereas the $\mathrm{WBC}\left(0^{\circ} \mathrm{C}\right)$ site had 
the least complex network. Interestingly, the proportion of positive/negative correlations also

307 changed according to the temperature; at higher temperatures, the proportion is even, while in

308 lower temperatures there was an increase in the number of positive correlations.

\section{Comparative functional profile of microbial communities on Deception Island volcano}

311 Functional profiles of metagenomes were compared using a multivariate method and hypothesis

312 test, and significant variations in all functional levels were observed between the $98{ }^{\circ} \mathrm{C}$ fumarole,

$313<80{ }^{\circ} \mathrm{C}$ fumaroles and glaciers. Clear differences between these three distinct sample groups were

314 observed through both the SEED Level 1 profile (Figure 3a) and SEED functional level through

315 PCA ordination (Figure 3b). Further, a distinct pattern between samples from the highest

316 temperature was observed. The prevalent core of functions among Deception samples were

317 "clustering-based subsystems", "carbohydrates", "amino acids and derivatives", "protein

318 metabolism", "RNA metabolism", "DNA metabolism” and "cofactors, vitamins, prosthetic groups

319 and pigments". Significant differences between sample groups and functions from level 1 of

320 SEED, calculated using Fisher's exact two-sided test and the Newcombe-Wilson method, showed

321 the highest abundance of genes belonging to the categories "DNA metabolism" $(p=0.046)$,

322 "protein metabolism" ( $p=0.049)$, and "phages, prophages, transposable elements and plasmids"

$323(p=3.97 \mathrm{e}-3)$ in the $98{ }^{\circ} \mathrm{C}$ fumarole in comparison with other fumaroles and glaciers. The

324 categories "nitrogen metabolism" ( $\mathrm{p}=1.07 \mathrm{e}-4)$, "photosynthesis" ( $p=5.07 \mathrm{e}-3)$, "sulfur

325 metabolism" ( $p=0.015)$, and "metabolism of aromatic compounds" ( $p=0.036)$ exhibited the

326 highest significant values in $<80{ }^{\circ} \mathrm{C}$ fumaroles when compared to the $98^{\circ} \mathrm{C}$ fumarole, and "motility

327 and chemotaxis" $(p=2.71 \mathrm{e}-8)$, "RNA metabolism" $(p=0.01)$, and "protein metabolism" $(p=$

328 0.023) when compared to glaciers. In contrast, observations for glaciers showed more genes 
associated with "carbohydrates" and "virulence, disease and defense" categories in comparison with the $98{ }^{\circ} \mathrm{C}$ fumarole $\left(p=0.049\right.$ and $p=0.036$, respectively) and $<80{ }^{\circ} \mathrm{C}$ fumaroles $(p=1.68 \mathrm{e}-$ 6 and $p=0.012$, respectively) (Figure 3c).

\section{Patterns of metabolic partitioning among extreme temperatures}

334 We observed different partitioning patterns of metabolic diversity according to environmental

potential significantly higher for functions associated with sulfate reduction $(p<0.001)$, dissimilatory nitrite reduction $(p<0.001)$ and carbon dioxide fixation $(p<0.001)$ when compared to other fumaroles and glaciers. Although sulfur metabolism was abundant among all temperatures, different metabolic pathways related to sulfur were observed according to the number of genes related to inorganic sulfur assimilation $(p<0.001)$ and sulfur oxidation $(p$ value

342 was not significant, $p<0.1$ ) were detected in $<80{ }^{\circ} \mathrm{C}$ fumaroles. In general, nitrogen metabolism was dominant in $<80{ }^{\circ} \mathrm{C}$ fumaroles when compared to other samples, with nitrate and nitrite

344 ammonification $(p<0.02)$, denitrification $(p<0.01)$, nitrogen fixation $(p<0.05)$ and ammonia

345 assimilation $(p<0.001)$ as the prevalent metabolic nitrogen pathways. All fumaroles showed a

346 similar abundance of genes belonging to sulfur oxidation, nitrate and nitrite ammonification, and

347 dissimilatory nitrite reduction. The genetic potential for carbon fixation was much higher in the 98

$348{ }^{\circ} \mathrm{C}$ fumarole $(p<0.01)$, whereas photosynthesis was mainly detected in the $<80{ }^{\circ} \mathrm{C}$ fumaroles and 349 glaciers. In glaciers, the genes identified within carbon metabolism were mainly associated with 350 heterotrophy and central carbon pathways, such as the pentose phosphate pathway and glycolysis, 351 as were respiration and fermentation. The function of carbon storage regulators was significantly 
352 higher in $<80{ }^{\circ} \mathrm{C}$ fumaroles, in addition to the observation of other carbon-related processes, such

353 as photosynthesis, fermentation, and carbon fixation (Figure 4).

\section{Community survival strategies under environmental extremes}

356 To understand community survival strategies under extreme temperature and geochemical

357 gradients, we selected genes in our metagenomes that are involved with stress response, DNA

358 repair, protein biosynthesis, and transport and chemotaxis. Although communities from all

359 samples were equally abundant in genes related to stress response, very distinct patterns of specific

360 responses were observed accordingly environmental temperature (Figure 4). The oxidative stress

361 response was markedly higher in the fumarole at $98{ }^{\circ} \mathrm{C}$, mainly represented by glutaredoxins,

362 glutathione (redox cycle) and rubrerythrin functions (all with $p<0.001$ in comparison with other

363 samples). Contrastingly, osmotic stress genes were prevalent in glaciers samples, represented

364 mainly by functions such as osmoregulation $(p<0.001)$, osmoprotectant $(y e h X)(p=0.01)$,

365 aquaporin $\mathrm{Z}(p=0.05)$ and synthesis of osmoregulated periplasmatic glucans $(p<0.001)$. The

366 abundance of genes related to heat and cold responses (thermal response) was distinctly distributed

367 among fumaroles and glaciers. General function of heat-shock proteins (including hsp $70 /$ dnaK)

368 were prevalent in glaciers and $<80{ }^{\circ} \mathrm{C}$ fumaroles $(p<0.001)$, whereas specific archaeal thermal

369 responses dominated the $98^{\circ} \mathrm{C}$ fumarole, such as thermosome chaperonin $(p<0.001,0.7 \%$ of total

370 relative abundance), as were bacterial and archaeal heat-shocks groEL/groES $(p<0.001)$. The

371 relative abundance of cold shock $\operatorname{csp} A$ was higher in $<80^{\circ} \mathrm{C}$ fumaroles, followed by glaciers $(p<$

372 0.001). Glaciers and $<80{ }^{\circ} \mathrm{C}$ fumaroles exhibited the highest abundance of dormancy and

373 sporulation function $(p<0.01)$ and all fumaroles had a prevalence of the universal stress protein

374 family $(p<0.01)$ (Figure 4$)$. 
Differences in abundance patterns of DNA repair, protein biosynthesis, transport and chemotaxis

377 were also observed across environmental temperatures (Supplementary Figure 2). Base excision

378 repair, recombination through $r e c U$ and reverse gyrase (all with $p<0.01$ ) were the main strategies

379 of DNA positive supercoiling and repair notably found in communities of the highest temperature

380 fumarole $\left(98^{\circ} \mathrm{C}\right)$. Strategies of DNA repair using $u v r A B C$ complex, recombination through recA

381 and photolyase were dominant in $<80{ }^{\circ} \mathrm{C}$ fumaroles and glaciers (all with $p<0.001$ ). Protein

382 biosynthesis genes were dominant in the highest temperature fumarole $\left(98^{\circ} \mathrm{C}\right)$; functions such as

383 universal GTPases $(p<0.01)$ and translation elongation factors in Archaea $(p<0.001)$ were

384 significantly higher when compared to the other samples. Chemotaxis genes were also prevalent

385 in the highest temperature fumarole $\left(98{ }^{\circ} \mathrm{C}\right)(p<0.001)$, as were several transport systems

386 (transport of $\mathrm{Ni}, \mathrm{Co}$, and $\mathrm{Zn}$ ) and ABC transporters (e.g. branched-chain amino acid, oligopeptide

387 and tungstate) (all with at least $p<0.05$ ). Mn transport and the ABC transporters of iron and 388 peptides were significantly higher in $<80{ }^{\circ} \mathrm{C}$ fumaroles (all with at least $p<0.05$ ) (Supplementary

389 Figure 2).

\section{Physical-chemical influence on taxonomic and functional diversity}

392 To identify key environmental drivers of community taxonomy (at phylum level) and function

393 (SEED level 1), Spearman correlations were calculated; then only significant $(p<0.05)$ and strong

394 correlations ( $r>-0.6$ or 0.6$)$ were considered. In general, the phyla that positively correlated with 395 temperature were Euryarchaeota, Crenarchaeota, Korarchaeota, Nanoarchaeota, Thermotogae, and 396 Aquificae, whereas several phyla were negatively correlated with temperature (e.g. Acidobacteria, 397 Bacteroidetes, Spirochaetes, Actinobacteria, Verrucumicrobia, Nitrospirae, Deinococcus- 
Thermus, and Gemmatimonadetes, among others) (Figure 5a). The phyla that negatively correlated with ammonia were Proteobacteria, Thaumarchaeota, Euryarchaeota, and Deferribacteres; those positively correlated were Firmicutes, Acidobacteria, Cyanobacteria, and Spirochaetes, among

401 others. All significant nitrate correlations were positive, including phyla such as Firmicutes, 402 Nitrospirae, Thermotogae, etc. Sulfate showed significant positive correlations with

403 Proteobacteria, Thaumarchaeota, Euryarchaeota, Deferribacteres and Crenarchaeota, and negative 404 correlations with phyla such as Acidobacteria, Cyanobacteria, Actinobacteria, and 405 Verrucomicrobia, among others. Other parameters exhibited positive and negative correlations 406 with several phyla, such as organic matter, organic carbon, B, Cu (uniquely negative correlations), 407 Fe (uniquely negative correlations), Na, K, Ca, Mg and Al (Figure 5a, Supplementary Table 3).

409 The functional categories (SEED level 1) which presented positive correlations with temperature 410 were "DNA metabolism", "nucleosides and nucleotides" and "RNA metabolism", and those which 411 exhibited negative correlations were "fatty acids, lipids and isoprenoids", "iron acquisition", 412 "metabolism of aromatic compounds", "phosphorus metabolism”, "photosynthesis", "secondary 413 metabolism", "stress response", and "sulfur metabolism” (Figure 5b). Ammonia was negatively 414 correlated with functions such as "carbohydrates", "motility and chemotaxis", "respiration" and 415 "RNA metabolism", whereas positive correlations comprised functions as "amino acids and 416 derivatives" and "cofactors, vitamins, prosthetic groups and pigments". Nitrate also presented 417 negative correlations with "carbohydrates", "dormancy and sporulation" and "phages, prophages, 418 transposable elements and plasmids". In contrast, sulfate was positively correlated with 419 "carbohydrates", "DNA metabolism", "motility and chemotaxis", "respiration" and "RNA 420 metabolism". Other parameters exhibited positive and negative correlations with several functions, 
421 such as organic matter, organic carbon, $\mathrm{B}, \mathrm{Cu}, \mathrm{Fe}, \mathrm{Si}, \mathrm{Na}, \mathrm{K}, \mathrm{Ca}, \mathrm{Mg}$ and $\mathrm{Al}$ (Figure 5b,

422 Supplementary Table 3).

423

424 Metabolic potential and survival strategies in MAGs

425 In general, the anvi'o pipeline using co-assembly showed the best binning results for our eighteen

426 metagenomes, generating a total of 158 MAGs. We included in our analyses only 1 MAG produced

427 through the idba-ud assembler and MaxBin binning since this MAG belonged to a taxon

428 (Calditrichia) which was not achieved through the anvi'o pipeline (Supplementary Figure 3,

429 Supplementary Table 4). From the 159 MAGs, 12 were assigned as Archaea through GTDB-Tk

430 and GhostKoala, belonging to Nitrososphaerales (Candidatus Nitrosocaldus according with

431 GhostKoala taxonomy) (2), Nitrosoarchaeum (1), Nitrosotenius (1), Nitrospumilus (1),

432 Desulfurococcales (Aeropyrum according with GhostKoala taxonomy) (1), Acidilobaceae (1),

433 Pyrodictiaceae (2) and Woesearchaeia (Nanoarchaeota) (3). The bacterial MAGs were classified

434 through GTDB-Tk and GhostKoala as the following phyla: Acidobacteriota (1), Aquificota (2),

435 Bacteroidota (92), Calditrichota (5), Campylobacterota (1), Chloroflexota (3), Cyanobacteriota

436 (1), Firmicutes (1), Nitrospirota (2), Patescibacteria (4) and Proteobacteria (35) (Supplementary

437 Figure 4, Supplementary Table 4). A total of 13 MAGs were considered as high quality and 82 as

438 medium quality drafts.

440 The MAGs were selected for functional annotation by their quality and based on groups related to

441 extremophiles and associated to sulfur and nitrogen metabolisms. These 11 selected MAGs were

442 assigned as $\quad$ DI_MAG_00003 (Sulfurimonas), DI_MAG_00004

443 (Hydrogenothermaceae/Persephonella), DI_MAG_00006 (Promineofilaceae/Candidatus 
Promineofilum),

DI_MAG_00010

(Caldilineaceae/Caldilinea),

DI_MAG_00011

445 (Thermonemataceae),

DI_MAG_00019

(Chitinophagaceae),

DI_MAG_00020

446 (Pyrodictiaceae/Pyrodictium),

DI_MAG_00021

(Dojkabacteria),

DI_MAG_00022

447 (Woesearchaeia/archaeon GW2011_AR20), DI_MAG_00049 (Nitrososphaerales/Candidatus

Nitrosocaldus) and DI_MAG_FBB2_12 (Calditrichia) (Table 1).

We identified in the high-quality DI_MAG_00004 (Hydrogenothermaceae/Persephonella, 97\%

completeness) genes for nitrate reduction (narGHI and nirA), denitrification (narGHI), nitrification (narGH), sulfate reduction (sat, cysH, sir), sulfur and thiosulfate oxidation (soxAXBYZ), and incomplete pathways for carbon fixation (Figure 6a). This MAG had several

454 genes associated with stress response, especially oxidative stress (e.g. superoxide reductase and 455 dismutase, rubrerythrin and rubredoxin) and thermal response (e.g. groES, $h s p 20$ and $h s p R$ ), as 456 different DNA repair mechanisms, including photolyase repair (Figure 6b). In general, genes 457 involved with the nitrogen cycle were identified in almost all selected MAGs, except for MAGs DI_MAG_00020, DI_MAG_00021, and DI_MAG_00022. Sulfate reduction genes were also

459 detected in different selected MAGs, except for MAGs DI_MAG_00020, DI_MAG_00021, DI_MAG_00022 and DI_MAG_FBB2_12. All MAGs had incomplete pathways for carbon

461 fixation, except for DI_MAG_00004 and DI_MAG_00021 (Figure 6a).

463 Different cold-shock genes were detected among MAGs; DI_MAG_00006 was the one which 464 presented more $c s p$ genes. We did not find any csp genes in archaeal MAGs (DI_MAG_00020, 465 DI_MAG_00022, and DI_MAG_00049). However, we observed genes in all selected MAGs that 466 were related to different heat-shock responses, including groEL/groES genes in DI_MAG_00004, 
DI_MAG_00020, and DI_MAG_00021. Thermosome (thsA) and reverse gyrase genes were

468 identified in all the selected MAGs assigned as Archaea (DI_MAG_00020, DI_MAG_00022, and

469 DI_MAG_00049). Although all MAGs showed the potential presence of oxidative stress response

470 (except DI_MAG_00049), rubrerythrin and rubredoxin genes were only observed in

471 DI_MAG_00004 and DI_MAG_00003. Different DNA repair mechanisms were identified in

472 selected MAGs, such as several recombination genes (rec genes), DNA mismatch repair (mut

473 genes), nucleotide excision repair ( $u v r$ genes), double-strand break repair (herA, only in archaeal-

474 selected MAGs) and photolyase repair (only in DI_MAG_00004) (Figure 6b).

475

476 Discussion

477 The primary goal of our study was to unveil how communities functionally respond to the 478 combination of environmental factors typical of polar marine volcanoes. Our results show that 479 regardless of proximity between fumaroles and glaciers on Deception Island, the community 480 function is strongly driven by the combination of contrasting environmental factors, as occurred 481 similar to what we previously observed for community composition and diversity (Bendia et al., 482 2018b). We detected some bacterial groups present in both glacier and fumarole sediments (most 483 notably the phyla Proteobacteria, Firmicutes, and Bacteroidetes), despite the strong gradients in 484 temperature, geochemistry and salinity. In addition, we observed specific groups that varied 485 according to the environmental temperature: the hyperthermophilic members belonging to 486 Crenarchaeota/Thermoprotei, Aquificae and Thermotoga phyla in the $98{ }^{\circ} \mathrm{C}$ fumarole, 487 Thaumarchaeota in $<80{ }^{\circ} \mathrm{C}$ fumaroles, and Acidobacteria and Verrucomicrobia in glaciers. These 488 patterns are consistent with previous work carried out on Deception Island using the same sample 489 set for diversity analysis (16S rRNA gene sequencing) (Bendia et al., 2018b), except for the 
490 Aquificae and Thermotogae phyla, which were not detected by that method. Furthermore, our

491 taxonomic patterns were also consistent with a previous report that observed similar members

492 along a temperature gradient ranging from 7.5 to $99^{\circ} \mathrm{C}$ in geothermal areas in Canada and New

493 Zealand (Sharp et al., 2014).

495 Surprisingly, our network analysis showed that the community interaction in the hottest fumarole

$496\left(98^{\circ} \mathrm{C}\right)$ was more complex and presented fewer positive interactions when compared to the lowest

497 temperatures, in contrast to previous studies that showed that community complexity decreases

498 with temperature increase (Cole et al., 2013; Merino et al., 2019; Sharp et al., 2014). Our results

499 suggest that hyperthermophilic temperatures on Deception probably trigger ecological interactions

500 between community members to modulate their resistance and resilience when facing strong

501 environmental stressors. Similar patterns of community interaction have been previously observed

502 in stressful conditions in the Atacama Desert (Mandakovic et al., 2018) and with increasing

503 temperature in anaerobic digestion (Lin et al., 2016), although these environmental conditions are

504 different from those found on Deception Island.

506 Correlation with environmental drivers varied among both taxonomic and functional groups. For

507 example, groups positively influenced by temperature, sulfate, and sodium were those mainly

508 abundant in fumaroles, while groups and functions prevalent in glaciers were positively correlated

509 with ammonia. These results indicate that the mosaic of environmental parameters shapes both

510 taxonomic and functional diversity of microbial communities. Indeed, we observed a partition of

511 metabolic diversity among the steep environmental gradients on Deception Island. Unlike previous

512 studies carried out at hydrothermal vents which pointed to metabolic functional redundancy at the 
513 community level (Galambos et al., 2019; Reveillaud et al., 2016), Deception communities showed

514 metabolic heterogeneity across the sharp temperature gradient. The observation of functional

515 redundancy despite the taxonomic variation has been observed in several environments such as

516 venting fluids from the Mariana back-arc, cold subseafloor ecosystems, freshwater and gut

517 microbiomes (Louca et al., 2016; Trembath-Reichert et al., 2019; Tully et al., 2018; Turnbaugh

518 and Gordon, 2009; Várbíró et al., 2017). The metabolic heterogeneity observed in our results

519 indicates that microbial communities on Deception harbor a remarkably diverse genetic content

520 that reflects the strong selective pressures caused by a remarkable interaction between the volcanic

521 activity, the marine environment, and the cryosphere.

523 The functional pattern clustered the samples by temperature, rather than by geographic location,

524 and showed that microbial communities on Deception Island are grouped by $98{ }^{\circ} \mathrm{C}$ fumarole, $<80$

$525{ }^{\circ} \mathrm{C}$ fumaroles and glaciers. The predominant metabolic potential in the hottest fumarole $\left(98^{\circ} \mathrm{C}\right)$

526 was mostly associated with reductive pathways, such as sulfate reduction, ammonification, and

527 dissimilatory nitrite reduction, and carbon fixation. We suggest that the hydrogen sulfide emissions

528 and hyperthermophilic conditions of this fumarole $\left(98^{\circ} \mathrm{C}\right)$ (Somoza et al., 2004) may decrease the

529 dissolved oxygen even in the superficial sediment layers, creating a steep redox gradient and

530 preferably selecting microorganisms with reductive and autotrophic pathways. In addition,

531 communities from the hottest fumarole $\left(98^{\circ} \mathrm{C}\right)$ exhibited several genes related to different adaptive

532 strategies, such as those associated with oxidative stress, specific archaeal heat-shock responses,

533 base excision repair, recombination ( $r e c U)$, reverse gyrase, protein biosynthesis, chemotaxis, and

534 ABC transporters. This reflects its primaries stress factors, including the fumarolic production of

535 hydrogen sulfide, which has a strong reductive power capable of causing oxidative stress, and 
536 hyperthermophilic temperature that induces disturbance to metabolic processes and cell-

537 component denaturation (Hedlund et al., 2015; Merino et al., 2019). Enrichment in genes involved

538 with chemotaxis was also observed in metagenomes from hydrothermal vents at Juan de Fuca

539 Ridge (Xie et al., 2011), but different DNA repair mechanisms were found when compared to

540 Deception metagenomes. Different types of ABC transporters were also detected in Ilheya

541 hydrothermal fields (Wang and Sun, 2017); reverse gyrase and thermosome mechanisms have

542 often been described in several groups of hyper(thermophilic) Archaea (Forterre et al., 2000;

543 Lemmens et al., 2018; Lulchev and Klostermeier, 2014).

545 In contrast, $<80{ }^{\circ} \mathrm{C}$ fumaroles were dominated by genes involved with different energetic and

546 chemolithotrophic pathways: sulfur oxidation, ammonification, denitrification, nitrogen fixation,

547 and dissimilatory nitrite reduction. This suggests a trend for both reductive and oxidative

548 pathways, as well as metabolic versatility and complex biogeochemical processes at the local

549 community level. Although genes related to sulfur and nitrogen pathways were detected in

550 glaciers, the majority of potential pathways for glacier communities were related to carbon

551 metabolism and heterotrophy. This lowest metabolic diversity can be explained by the decrease of

552 marine and volcanic geochemicals (e.g. sulfate) towards glaciers (Supplementary Table 1), making

553 these substrates unavailable for exploiting different energy sources, as occurs in fumaroles. The

$554<80{ }^{\circ} \mathrm{C}$ fumaroles and glacier communities harbored mechanisms for both heat and cold-shock

555 genes, dormancy and sporulation functions, and DNA repair mechanisms through $u v r A B C$

556 complex, recA, and photolyase. Diverse survival strategies in $<80{ }^{\circ} \mathrm{C}$ fumaroles and glaciers might

557 be explained by community exposure to fluctuating temperatures and redox conditions that are

558 more variable when compared to the stability of hottest fumarole, which maintains the 
hyperthermophilic temperatures and hydrogen sulfide emissions for long periods. Further, glacier communities exhibited more genes associated with osmotic stress, which reflects the low liquid water availability due to the predominant freezing conditions of the Antarctic ecosystems (Wei et al., 2016).

Although several studies have shown a quantitative decrease in microbial diversity as temperature increases in both geothermal and hydrothermal ecosystems (Cole et al., 2013; Sharp et al., 2014), little is known about how temperature affects ecosystem functioning due to inhibition of key

567 metabolic enzymes or pathways (Hedlund et al., 2015). Despite the limitation of metagenomics in revealing the truly active microbial metabolic pathways, our results increase understanding of the

569 potential temperature limits on different microbial metabolism at the community level and 570 encourage more studies to elucidate the direct effect of temperature extremes on specific 571 biogeochemical processes in Antarctic volcanic ecosystems.

573 The 159 MAGs recovered from the Deception Island volcano comprised a broad phylogenetic 574 range of archaeal and bacterial phyla. The 11 MAGs selected for annotation included 575 hyperthermophilic and thermophilic lineages, as well as lineages containing homologs of different 576 predicted sulfur and nitrogen pathways, and archaeal groups underrepresented in genome data, 577 such as Ca. Nitrosocaldus and Nanoarchaeota/Woesearchaeia. Since Ca. Nitrosocaldus was 578 previously reported only in terrestrial geothermal environments (Abby et al., 2018; Daebeler et al., 579 2018; Torre et al., 2008), their presence on Deception fumaroles represents a novel outcome for 580 the ecological distribution of thermophilic ammonia-oxidizing Archaea and encourages further 581 investigation to better understand their role in marine volcanic ecosystems. Furthermore, the 
majority of our selected MAGs are equipped with gene-encoding proteins that protect cells against several stressful conditions, including cold and heat-shock, carbon starvation, oxidative and

584 periplasmic stress, and DNA damage, likely enabling survival and adaptation of these

585 microorganisms to a broad combination of extreme parameters. One of our MAGs was closely 586 related to archaeon GW2011_AR20, which is an uncultivated and underrepresented

587 Nanoarchaeota/Woesearchaeia member described previously in aquifer samples and appears to 588 have a symbiotic or pathogenic lifestyle due to the small genome size and lack of some 589 biosynthesis pathways (Castelle et al., 2015). The genome analysis of our Woesearchaeia MAG 590 (archaeon GW2011_AR20, DI_MAG_00022) suggests a novel putative thermophilic lifestyle or 591 at least a potential heat tolerance for this lineage due to the (i) lack of cold-shock genes, (these 592 genes are mostly absent in the genomes of thermophilic archaea, while usually present in 593 psychrophilic/mesophilic archaeal members (Cavicchioli, 2006; Giaquinto et al., 2007), and (ii)

594 the presence of reverse gyrase, thermosome and other heat-shock genes (e.g. groES) that are 595 essentially related to (hyper)thermophiles and heat response. Although these heat-shock genes 596 were also detected in some mesophilic archaeal lineages within Halobacteria, Thaumarchaeota, 597 and Methanosarcina spp. (Lemmens et al., 2018), reverse gyrase is the only protein found 598 ubiquitously in hyperthermophilic organisms, but absent in mesophiles (Catchpole and Forterre, 599 2019), pointing to this Woesearchaeia member as a likely thermophile or hyperthermophile.

\section{Conclusion}

602 By combining the annotation of reads and contigs together with genome reconstruction from 603 metagenomic data, we provide the first genetic and genomic evidence that microorganisms 604 inhabiting the Deception Island volcano possess a variety of adaptive strategies and metabolic 
processes that are shaped by steep environmental gradients. We observed that hyperthermophilic temperatures $\left(98^{\circ} \mathrm{C}\right)$ preferably select microorganisms with reductive and autotrophic pathways,

607 while communities from fumaroles $<80^{\circ} \mathrm{C}$ show a high metabolic versatility with both reductive

608 and oxidative pathways, and glaciers harbor communities with metabolic processes especially

609 related to carbon metabolism and heterotrophy. Survival strategies of microorganisms from the

610 hottest fumarole are very specialized in responding to the hyperthermophilic temperatures and

611 oxidative stress, while $<80{ }^{\circ} \mathrm{C}$ fumaroles and glacier communities possesses a variety of strategies

612 that are capable of responding to fluctuating redox and temperature conditions. We found more

613 complex and negative interactions among the communities from the hottest fumarole $\left(98{ }^{\circ} \mathrm{C}\right)$,

614 which indicate that the strong environmental stressors probably trigger competitive associations

615 among community members. Furthermore, through the reconstruction of MAGs, we were able to

616 clarify a putative novel thermophilic lifestyle for a Woesearchaeia member and a marine lifestyle

617 for a $\mathrm{Ca}$. Nitrosocaldus lineage. Our work represents, as far as we know, the first study to reveal

618 through shotgun metagenomics the response of microbial functional diversity to the extreme

619 temperature gradient $\left(0\right.$ to $\left.98^{\circ} \mathrm{C}\right)$ of an Antarctic volcano. Furthermore, our study was one of the

620 first to recover MAGs from these ecosystems and it provides new insights regarding the metabolic

621 and survival capabilities of different extremophiles inhabiting the Antarctic volcanoes.

622

623

624

625

626

627 


\section{Author Contributions}

$629 \mathrm{AB}$ collected the samples, conceived and designed the experiments, performed the experiments,

630 analyzed the data, performed bioinformatic analysis, wrote the paper, and prepared figures and

631 tables. LL contributed to discussion of metagenome-assembled genome analysis, discussed the

632 data, wrote the paper, and reviewed drafts of the paper. LM performed network analysis, wrote the

633 paper, and reviewed drafts of the paper. CS discussed the data, wrote the paper, and reviewed

634 drafts of the paper. BB discussed the data, wrote and reviewed drafts of the paper. VP conceived

635 and designed the experiments, contributed reagents, materials, and analysis tools, and wrote and

636 reviewed drafts of the paper.

\section{Funding}

639 This study was part of the projects Microsfera (CNPq 407816/2013-5) and INCT-Criosfera (CNPq

640 028306/2009) and supported by the Brazilian National Council of Technological and Scientific

641 Development (CNPq) and the Brazilian Antarctic Program (ProAntar). The São Paulo Research

642 Foundation - FAPESP supported ABs Doctoral fellowship (2012/23241-0).

643

\section{Conflict of Interest Statement}

645 The authors declare that the research was conducted in the absence of any commercial or financial 646 relationships that could be construed as a potential conflict of interest. 


\section{Acknowledgments}

652 We thank the captain and the crew of the research polar vessel Almirante Maximiano, Dr. Luiz

653 Henrique Rosa, Dr. Wânia Duleba, and Dr. Antônio Carlos Rocha Campos for their support in

654 sampling. We are very thankful to LECOM's research team and Rosa C. Gamba for their scientific

655 support.

656

657 


\section{References}

659

660

661

662

663

664

665

666

667

668

669

670

671

672

673

674

675

676

677

678

679

680

681

682

683

684

685

686

687

688

689

690

691

692

693

694

695

696

697

698

699

700

701

Abby, S.S., Melcher, M., Kerou, M., Krupovic, M., Stieglmeier, M., Rossel, C., Pfeifer, K., Schleper, C., 2018. Candidatus Nitrosocaldus cavascurensis, an Ammonia Oxidizing, Extremely Thermophilic Archaeon with a Highly Mobile Genome. Front. Microbiol. 9. https://doi.org/10.3389/fmicb.2018.00028

Alneberg, J., Bjarnason, B.S., de Bruijn, I., Schirmer, M., Quick, J., Ijaz, U.Z., Loman, N.J., Andersson, A.F., Quince, C., 2013. CONCOCT: Clustering cONtigs on COverage and ComposiTion. ArXiv13124038 Q-Bio.

Altschul, S.F., Gish, W., Miller, W., Myers, E.W., Lipman, D.J., 1990. Basic local alignment search tool. J. Mol. Biol. 215, 403-410. https://doi.org/10.1016/S0022-2836(05)80360-2

Amenábar, M.J., Flores, P.A., Pugin, B., Boehmwald, F.A., Blamey, J.M., 2013. Archaeal diversity from hydrothermal systems of Deception Island, Antarctica. Polar Biol. 36, 373380. https://doi.org/10.1007/s00300-012-1267-3

Antranikian, G., Suleiman, M., Schäfers, C., Adams, M.W.W., Bartolucci, S., Blamey, J.M., Birkeland, N.-K., Bonch-Osmolovskaya, E., da Costa, M.S., Cowan, D., Danson, M., Forterre, P., Kelly, R., Ishino, Y., Littlechild, J., Moracci, M., Noll, K., Oshima, T., Robb, F., Rossi, M., Santos, H., Schönheit, P., Sterner, R., Thauer, R., Thomm, M., Wiegel, J., Stetter, K.O., 2017. Diversity of bacteria and archaea from two shallow marine hydrothermal vents from Vulcano Island. Extremophiles 21, 733-742. https://doi.org/10.1007/s00792-017-0938-y

Aziz, R.K., Bartels, D., Best, A.A., DeJongh, M., Disz, T., Edwards, R.A., Formsma, K., Gerdes, S., Glass, E.M., Kubal, M., Meyer, F., Olsen, G.J., Olson, R., Osterman, A.L., Overbeek, R.A., McNeil, L.K., Paarmann, D., Paczian, T., Parrello, B., Pusch, G.D., Reich, C., Stevens, R., Vassieva, O., Vonstein, V., Wilke, A., Zagnitko, O., 2008. The RAST Server: Rapid Annotations using Subsystems Technology. BMC Genomics 9, 75. https://doi.org/10.1186/1471-2164-9-75

Baker, P.E., McReath, I., Harvey, M.R., Roobol, M.J., Davies, T.G., 1975. The geology of the South Shetland Islands: V. Volcanic evolution of Deception Island. British Antarctic Survey, Cambridge.

Bartolini, S., Geyer, A., Martí, J., Pedrazzi, D., Aguirre-Díaz, G., 2014. Volcanic hazard on Deception Island (South Shetland Islands, Antarctica). J. Volcanol. Geotherm. Res. 285, 150-168. https://doi.org/10.1016/j.jvolgeores.2014.08.009

Bastian, M., Heymann, S., Jacomy, M., 2009. Gephi: An Open Source Software for Exploring and Manipulating Networks, in: Third International AAAI Conference on Weblogs and Social Media. Presented at the Third International AAAI Conference on Weblogs and Social Media.

Bendia, A.G., Araujo, G.G., Pulschen, A.A., Contro, B., Duarte, R.T.D., Rodrigues, F., Galante, D., Pellizari, V.H., 2018a. Surviving in hot and cold: psychrophiles and thermophiles from Deception Island volcano, Antarctica. Extremophiles 22, 917-929. https://doi.org/10.1007/s00792-018-1048-1

Bendia, A.G., Signori, C.N., Franco, D.C., Duarte, R.T.D., Bohannan, B.J.M., Pellizari, V.H., 2018b. A Mosaic of Geothermal and Marine Features Shapes Microbial Community 
Structure on Deception Island Volcano, Antarctica. Front. Microbiol. 9. https://doi.org/10.3389/fmicb.2018.00899

Bowers, R.M., Kyrpides, N.C., Stepanauskas, R., Harmon-Smith, M., Doud, D., Reddy, T.B.K., Schulz, F., Jarett, J., Rivers, A.R., Eloe-Fadrosh, E.A., Tringe, S.G., Ivanova, N.N., Copeland, A., Clum, A., Becraft, E.D., Malmstrom, R.R., Birren, B., Podar, M., Bork, P., Weinstock, G.M., Garrity, G.M., Dodsworth, J.A., Yooseph, S., Sutton, G., Glöckner, F.O., Gilbert, J.A., Nelson, W.C., Hallam, S.J., Jungbluth, S.P., Ettema, T.J.G., Tighe, S., Konstantinidis, K.T., Liu, W.-T., Baker, B.J., Rattei, T., Eisen, J.A., Hedlund, B., McMahon, K.D., Fierer, N., Knight, R., Finn, R., Cochrane, G., Karsch-Mizrachi, I., Tyson, G.W., Rinke, C., Lapidus, A., Meyer, F., Yilmaz, P., Parks, D.H., Eren, A.M., Schriml, L., Banfield, J.F., Hugenholtz, P., Woyke, T., 2017. Minimum information about a single amplified genome (MISAG) and a metagenome-assembled genome (MIMAG) of bacteria and archaea. Nat. Biotechnol. 35, 725-731. https://doi.org/10.1038/nbt.3893

Brettin, T., Davis, J.J., Disz, T., Edwards, R.A., Gerdes, S., Olsen, G.J., Olson, R., Overbeek, R., Parrello, B., Pusch, G.D., Shukla, M., Thomason, J.A., Stevens, R., Vonstein, V., Wattam, A.R., Xia, F., 2015. RASTtk: A modular and extensible implementation of the RAST algorithm for building custom annotation pipelines and annotating batches of genomes. Sci. Rep. 5, 8365. https://doi.org/10.1038/srep08365

Carrión, O., Miñana-Galbis, D., Montes, M.J., Mercadé, E., 2011. Pseudomonas deceptionensis sp. nov., a psychrotolerant bacterium from the Antarctic. Int. J. Syst. Evol. Microbiol. 61, 2401-2405. https://doi.org/10.1099/ijs.0.024919-0

Castelle, C.J., Wrighton, K.C., Thomas, B.C., Hug, L.A., Brown, C.T., Wilkins, M.J., Frischkorn, K.R., Tringe, S.G., Singh, A., Markillie, L.M., Taylor, R.C., Williams, K.H., Banfield, J.F., 2015. Genomic Expansion of Domain Archaea Highlights Roles for Organisms from New Phyla in Anaerobic Carbon Cycling. Curr. Biol. 25, 690-701. https://doi.org/10.1016/j.cub.2015.01.014

Catchpole, R.J., Forterre, P., 2019. The Evolution of Reverse Gyrase Suggests a Nonhyperthermophilic Last Universal Common Ancestor. Mol. Biol. Evol. 36, 27372747. https://doi.org/10.1093/molbev/msz180

Cavicchioli, R., 2006. Cold-adapted archaea. Nat. Rev. Microbiol. 4, 331-343. https://doi.org/10.1038/nrmicro1390

Centurion, V.B., Delforno, T.P., Lacerda-Júnior, G.V., Duarte, A.W.F., Silva, L.J., Bellini, G.B., Rosa, L.H., Oliveira, V.M., 2019. Unveiling resistome profiles in the sediments of an Antarctic volcanic island. Environ. Pollut. 255, 113240. https://doi.org/10.1016/j.envpol.2019.113240

Chaumeil, P.-A., Mussig, A.J., Hugenholtz, P., Parks, D.H., 2020. GTDB-Tk: a toolkit to classify genomes with the Genome Taxonomy Database. Bioinformatics 36, 1925-1927. https://doi.org/10.1093/bioinformatics/btz848

Cole, J.K., Peacock, J.P., Dodsworth, J.A., Williams, A.J., Thompson, D.B., Dong, H., Wu, G., Hedlund, B.P., 2013. Sediment microbial communities in Great Boiling Spring are controlled by temperature and distinct from water communities. ISME J. 7, 718-729. https://doi.org/10.1038/ismej.2012.157

Daebeler, A., Herbold, C.W., Vierheilig, J., Sedlacek, C.J., Pjevac, P., Albertsen, M., Kirkegaard, R.H., de la Torre, J.R., Daims, H., Wagner, M., 2018. Cultivation and Genomic Analysis of "Candidatus Nitrosocaldus islandicus," an Obligately Thermophilic, Ammonia- 
Oxidizing Thaumarchaeon from a Hot Spring Biofilm in Graendalur Valley, Iceland. Front. Microbiol. 9. https://doi.org/10.3389/fmicb.2018.00193

Dick, G.J., 2019. The microbiomes of deep-sea hydrothermal vents: distributed globally, shaped locally. Nat. Rev. Microbiol. 17, 271-283. https://doi.org/10.1038/s41579-019-0160-2

Eren, A.M., Esen, Ö.C., Quince, C., Vineis, J.H., Morrison, H.G., Sogin, M.L., Delmont, T.O., 2015. Anvi'o: an advanced analysis and visualization platform for 'omics data. PeerJ 3, e1319. https://doi.org/10.7717/peerj.1319

Feldbauer, R., Schulz, F., Horn, M., Rattei, T., 2015. Prediction of microbial phenotypes based on comparative genomics. BMC Bioinformatics 16, S1. https://doi.org/10.1186/1471-210516-S14-S1

Fermani, P., Mataloni, G., Van de Vijver, B., 2007. Soil microalgal communities on an antarctic active volcano (Deception Island, South Shetlands). Polar Biol. 30, 1381-1393. https://doi.org/10.1007/s00300-007-0299-6

Finn, R.D., Clements, J., Eddy, S.R., 2011. HMMER web server: interactive sequence similarity searching. Nucleic Acids Res. 39, W29-W37. https://doi.org/10.1093/nar/gkr367

Forterre, P., Tour, C.B. de la, Philippe, H., Duguet, M., 2000. Reverse gyrase from hyperthermophiles: probable transfer of a thermoadaptation trait from Archaea to Bacteria. Trends Genet. 16, 152-154. https://doi.org/10.1016/S0168-9525(00)01980-6

Freilich, S., Kreimer, A., Meilijson, I., Gophna, U., Sharan, R., Ruppin, E., 2010. The large-scale organization of the bacterial network of ecological co-occurrence interactions. Nucleic Acids Res. 38, 3857-3868. https://doi.org/10.1093/nar/gkq118

Friedman, J., Alm, E.J., 2012. Inferring Correlation Networks from Genomic Survey Data. PLoS Comput. Biol. 8. https://doi.org/10.1371/journal.pcbi.1002687

Galambos, D., Anderson, R.E., Reveillaud, J., Huber, J.A., 2019. Genome-resolved metagenomics and metatranscriptomics reveal niche differentiation in functionally redundant microbial communities at deep-sea hydrothermal vents. Environ. Microbiol. 21, 4395-4410. https://doi.org/10.1111/1462-2920.14806

Galperin, M.Y., Makarova, K.S., Wolf, Y.I., Koonin, E.V., 2015. Expanded microbial genome coverage and improved protein family annotation in the COG database. Nucleic Acids Res. 43, D261-D269. https://doi.org/10.1093/nar/gku1223

Geyer, A., Álvarez-Valero, A.M., Gisbert, G., Aulinas, M., Hernández-Barreña, D., Lobo, A., Marti, J., 2019. Deciphering the evolution of Deception Island's magmatic system. Sci. Rep. 9, 373. https://doi.org/10.1038/s41598-018-36188-4

Giaquinto, L., Curmi, P.M.G., Siddiqui, K.S., Poljak, A., DeLong, E., DasSarma, S., Cavicchioli, R., 2007. Structure and Function of Cold Shock Proteins in Archaea. J. Bacteriol. 189, 5738-5748. https://doi.org/10.1128/JB.00395-07

Hedlund, B.P., Thomas, S.C., Dodsworth, J.A., Zhang, C.L., 2015. Life in High-Temperature Environments, in: Manual of Environmental Microbiology. John Wiley \& Sons, Ltd, pp. 4.3.4-1-4.3.4-15. https://doi.org/10.1128/9781555818821.ch4.3.4

Herbold, C.W., McDonald, I.R., Cary, S.C., 2014. Microbial Ecology of Geothermal Habitats in Antarctica, in: Cowan, D.A. (Ed.), Antarctic Terrestrial Microbiology: Physical and Biological Properties of Antarctic Soils. Springer, Berlin, Heidelberg, pp. 181-215. https://doi.org/10.1007/978-3-642-45213-0_10

Hyatt, D., Chen, G.-L., LoCascio, P.F., Land, M.L., Larimer, F.W., Hauser, L.J., 2010. Prodigal: prokaryotic gene recognition and translation initiation site identification. BMC Bioinformatics 11, 119. https://doi.org/10.1186/1471-2105-11-119 
Joshi, N., Fass, J., 2011. Sickle: A sliding-window, adaptive, quality-based trimming tool for FastQ files (Version 1.33) [Software].

Kanehisa, M., Goto, S., 2000. KEGG: Kyoto Encyclopedia of Genes and Genomes. Nucleic Acids Res. 28, 27-30. https://doi.org/10.1093/nar/28.1.27

Kanehisa, M., Sato, Y., Morishima, K., 2016. BlastKOALA and GhostKOALA: KEGG Tools for Functional Characterization of Genome and Metagenome Sequences. J. Mol. Biol., Computation Resources for Molecular Biology 428, 726-731. https://doi.org/10.1016/j.jmb.2015.11.006

Keegan, K.P., Glass, E.M., Meyer, F., 2016. MG-RAST, a Metagenomics Service for Analysis of Microbial Community Structure and Function, in: Martin, F., Uroz, S. (Eds.), Microbial Environmental Genomics (MEG), Methods in Molecular Biology. Springer, New York, NY, pp. 207-233. https://doi.org/10.1007/978-1-4939-3369-3_13

Langmead, B., Salzberg, S.L., 2012. Fast gapped-read alignment with Bowtie 2. Nat. Methods 9, 357-359. https://doi.org/10.1038/nmeth.1923

Lemmens, L., Baes, R., Peeters, E., 2018. Heat shock response in archaea. Emerg. Top. Life Sci. 2, 581-593. https://doi.org/10.1042/ETLS20180024

Lezcano, M.Á., Moreno-Paz, M., Carrizo, D., Prieto-Ballesteros, O., Fernández-Martínez, M.Á., Sánchez-García, L., Blanco, Y., Puente-Sánchez, F., de Diego-Castilla, G., GarcíaVilladangos, M., Fairén, A.G., Parro, V., 2019. Biomarker Profiling of Microbial Mats in the Geothermal Band of Cerro Caliente, Deception Island (Antarctica): Life at the Edge of Heat and Cold. Astrobiology 19, 1490-1504. https://doi.org/10.1089/ast.2018.2004

Li, D., Liu, C.-M., Luo, R., Sadakane, K., Lam, T.-W., 2015. MEGAHIT: an ultra-fast single-node solution for large and complex metagenomics assembly via succinct de Bruijn graph. Bioinformatics 31, 1674-1676. https://doi.org/10.1093/bioinformatics/btv033

Lin, Q., De Vrieze, J., Li, J., Li, X., 2016. Temperature affects microbial abundance, activity and interactions in anaerobic digestion. Bioresour. Technol. 209, 228-236. https://doi.org/10.1016/j.biortech.2016.02.132

Llarch, À., Logan, N.A., Castellví, J., Prieto, M.J., Guinea, J., 1997. Isolation and Characterization of Thermophilic Bacillus spp. from Geothermal Environments on Deception Island, South Shetland Archipelago. Microb. Ecol. 34, 58-65. https://doi.org/10.1007/s002489900034

Louca, S., Parfrey, L.W., Doebeli, M., 2016. Decoupling function and taxonomy in the global ocean microbiome. Science 353, 1272-1277. https://doi.org/10.1126/science.aaf4507

Lulchev, P., Klostermeier, D., 2014. Reverse gyrase-recent advances and current mechanistic understanding of positive DNA supercoiling. Nucleic Acids Res. 42, 8200-8213. https://doi.org/10.1093/nar/gku589

Mandakovic, D., Rojas, C., Maldonado, J., Latorre, M., Travisany, D., Delage, E., Bihouée, A., Jean, G., Díaz, F.P., Fernández-Gómez, B., Cabrera, P., Gaete, A., Latorre, C., Gutiérrez, R.A., Maass, A., Cambiazo, V., Navarrete, S.A., Eveillard, D., González, M., 2018. Structure and co-occurrence patterns in microbial communities under acute environmental stress reveal ecological factors fostering resilience. Sci. Rep. 8, 5875. https://doi.org/10.1038/s41598-018-23931-0

Markowitz, V.M., Mavromatis, K., Ivanova, N.N., Chen, I.-M.A., Chu, K., Kyrpides, N.C., 2009. IMG ER: a system for microbial genome annotation expert review and curation. Bioinformatics 25, 2271-2278. https://doi.org/10.1093/bioinformatics/btp393 
Merino, N., Aronson, H.S., Bojanova, D.P., Feyhl-Buska, J., Wong, M.L., Zhang, S., Giovannelli, D., 2019. Living at the Extremes: Extremophiles and the Limits of Life in a Planetary Context. Front. Microbiol. 10. https://doi.org/10.3389/fmicb.2019.00780

Muñoz, P.A., Flores, P.A., Boehmwald, F.A., Blamey, J.M., 2011. Thermophilic bacteria present in a sample from Fumarole Bay, Deception Island. Antarct. Sci. 23, 549-555. https://doi.org/10.1017/S0954102011000393

Muñoz-Martín, A., Catalán, M., Martín-Dávila, J., Carbó, A., 2005. Upper crustal structure of Deception Island area (Bransfield Strait, Antarctica) from gravity and magnetic modelling. Antarct. Sci. 17, 213-224. https://doi.org/10.1017/S0954102005002622

Nakagawa, T., Takai, K., Suzuki, Y., Hirayama, H., Konno, U., Tsunogai, U., Horikoshi, K., 2006. Geomicrobiological exploration and characterization of a novel deep-sea hydrothermal system at the TOTO caldera in the Mariana Volcanic Arc. Environ. Microbiol. 8, 37-49. https://doi.org/10.1111/j.1462-2920.2005.00884.x

Newman, M., 2003. The Structure and Function of Complex Networks. Struct. Funct. Complex Netw. 45, 167-256. https://doi.org/10.1137/S003614450342480

Oksanen, J., 2007. vegan : Community Ecology Package. R package version 1.8-5 [WWW Document]. URL /paper/vegan-\%3A-Community-Ecology-Package.-R-package-1.8-5Oksanen/ce62be133614e05a8a63c39743e42a43765a5db0 (accessed 6.3.20).

Parks, D.H., Imelfort, M., Skennerton, C.T., Hugenholtz, P., Tyson, G.W., 2015. CheckM: assessing the quality of microbial genomes recovered from isolates, single cells, and metagenomes. Genome Res. 25, 1043-1055. https://doi.org/10.1101/gr.186072.114

Parks, D.H., Tyson, G.W., Hugenholtz, P., Beiko, R.G., 2014. STAMP: statistical analysis of taxonomic and functional profiles. Bioinformatics 30, 3123-3124. https://doi.org/10.1093/bioinformatics/btu494

Peng, Y., Leung, H.C.M., Yiu, S.M., Chin, F.Y.L., 2012. IDBA-UD: a de novo assembler for single-cell and metagenomic sequencing data with highly uneven depth. Bioinformatics 28, 1420-1428. https://doi.org/10.1093/bioinformatics/bts174

Price, R.E., Giovannelli, D., 2017. A Review of the Geochemistry and Microbiology of Marine Shallow-Water Hydrothermal Vents, in: Reference Module in Earth Systems and Environmental Sciences. Elsevier. https://doi.org/10.1016/B978-0-12-409548-9.09523-3

Reveillaud, J., Reddington, E., McDermott, J., Algar, C., Meyer, J.L., Sylva, S., Seewald, J., German, C.R., Huber, J.A., 2016. Subseafloor microbial communities in hydrogen-rich vent fluids from hydrothermal systems along the Mid-Cayman Rise. Environ. Microbiol. 18, 1970-1987. https://doi.org/10.1111/1462-2920.13173

Rey, J., Somoza, L., Martínez-Frías, J., 1995. Tectonic, volcanic, and hydrothermal event sequence on Deception Island (Antarctica). Geo-Mar. Lett. 15, 1-8. https://doi.org/10.1007/BF01204491

Seemann, T., 2014. Prokka: rapid prokaryotic genome annotation. Bioinformatics 30, 2068-2069. https://doi.org/10.1093/bioinformatics/btu153

Sharp, C.E., Brady, A.L., Sharp, G.H., Grasby, S.E., Stott, M.B., Dunfield, P.F., 2014. Humboldt's spa: microbial diversity is controlled by temperature in geothermal environments. ISME J. 8, 1166-1174. https://doi.org/10.1038/ismej.2013.237

Somoza, L., Martínez-Frías, J., Smellie, J.L., Rey, J., Maestro, A., 2004. Evidence for hydrothermal venting and sediment volcanism discharged after recent short-lived volcanic eruptions at Deception Island, Bransfield Strait, Antarctica. Mar. Geol. 203, 119-140. https://doi.org/10.1016/S0025-3227(03)00285-8 
883

Stanley, S.O., Rose, A.H., Smith, J.E., 1967. Bacteria and yeasts from lakes on Deception Island. Philos. Trans. R. Soc. Lond. B. Biol. Sci. 252, 199-207. https://doi.org/10.1098/rstb.1967.0012

Takai, K., Komatsu, T., Inagaki, F., Horikoshi, K., 2001. Distribution of Archaea in a Black Smoker Chimney Structure. Appl. Environ. Microbiol. 67, 3618-3629. https://doi.org/10.1128/AEM.67.8.3618-3629.2001

Torre, J.R.D.L., Walker, C.B., Ingalls, A.E., Könneke, M., Stahl, D.A., 2008. Cultivation of a thermophilic ammonia oxidizing archaeon synthesizing crenarchaeol. Environ. Microbiol. 10, 810-818. https://doi.org/10.1111/j.1462-2920.2007.01506.x

Trembath-Reichert, E., Butterfield, D.A., Huber, J.A., 2019. Active subseafloor microbial communities from Mariana back-arc venting fluids share metabolic strategies across different thermal niches and taxa. ISME J. 13, 2264-2279. https://doi.org/10.1038/s41396019-0431-y

Tully, B.J., Wheat, C.G., Glazer, B.T., Huber, J.A., 2018. A dynamic microbial community with high functional redundancy inhabits the cold, oxic subseafloor aquifer. ISME J. 12, 1-16. https://doi.org/10.1038/ismej.2017.187

Turnbaugh, P.J., Gordon, J.I., 2009. The core gut microbiome, energy balance and obesity. J. Physiol. 587, 4153-4158. https://doi.org/10.1113/jphysiol.2009.174136

Várbíró, G., Görgényi, J., Tóthmérész, B., Padisák, J., Hajnal, É., Borics, G., 2017. Functional redundancy modifies species-area relationship for freshwater phytoplankton. Ecol. Evol. 7, 9905-9913. https://doi.org/10.1002/ece3.3512

Wang, H., Sun, L., 2017. Comparative metagenomics reveals insights into the deep-sea adaptation mechanism of the microorganisms in Iheya hydrothermal fields. World J. Microbiol. Biotechnol. 33, 86. https://doi.org/10.1007/s11274-017-2255-0

Ward, L., Taylor, M.W., Power, J.F., Scott, B.J., McDonald, I.R., Stott, M.B., 2017. Microbial community dynamics in Inferno Crater Lake, a thermally fluctuating geothermal spring. ISME J. 11, 1158-1167. https://doi.org/10.1038/ismej.2016.193

Wei, S.T.S., Lacap-Bugler, D.C., Lau, M.C.Y., Caruso, T., Rao, S., de los Rios, A., Archer, S.K., Chiu, J.M.Y., Higgins, C., Van Nostrand, J.D., Zhou, J., Hopkins, D.W., Pointing, S.B., 2016. Taxonomic and Functional Diversity of Soil and Hypolithic Microbial Communities in Miers Valley, McMurdo Dry Valleys, Antarctica. Front. Microbiol. 7. https://doi.org/10.3389/fmicb.2016.01642

Wickham, H., 2011. ggplot2. WIREs Comput. Stat. 3, 180-185. https://doi.org/10.1002/wics.147

Wilke, A., Harrison, T., Wilkening, J., Field, D., Glass, E.M., Kyrpides, N., Mavrommatis, K., Meyer, F., 2012. The M5nr: a novel non-redundant database containing protein sequences and annotations from multiple sources and associated tools. BMC Bioinformatics 13, 141. https://doi.org/10.1186/1471-2105-13-141

Wu, Y.-W., Simmons, B.A., Singer, S.W., 2016. MaxBin 2.0: an automated binning algorithm to recover genomes from multiple metagenomic datasets. Bioinformatics 32, 605-607. https://doi.org/10.1093/bioinformatics/btv638

Xie, W., Wang, F., Guo, L., Chen, Z., Sievert, S.M., Meng, J., Huang, G., Li, Y., Yan, Q., Wu, S., Wang, X., Chen, S., He, G., Xiao, X., Xu, A., 2011. Comparative metagenomics of microbial communities inhabiting deep-sea hydrothermal vent chimneys with contrasting chemistries. ISME J. 5, 414-426. https://doi.org/10.1038/ismej.2010.144

Zhang, J.-Z., Millero, F.J., 1993. The products from the oxidation of H2S in seawater. Geochim. Cosmochim. Acta 57, 1705-1718. https://doi.org/10.1016/0016-7037(93)90108-9 


\section{Figures legends}

Figure 1. The sampling map with the location of Antarctic Peninsula (A) and Deception Island,

935 with Fumarole Bay and Whalers Bay geothermal sites highlighted (B). Distribution of collected

936 samples across environmental gradients at studied geothermal sites are described in C for Fumarole

937 Bay and D for Whalers Bay. In situ temperatures are represented in blue (glaciers) and orange

938 (fumaroles). The arrow indicates the direction of low and high values of temperature, salinity and

939 volcanic compounds, such as sulfate. Figure was retrieved from Bendia et al., $2018 \mathrm{~b}$.

941 Figure 2. Relative abundances of microbial community taxonomy based on annotation of reads

942 from shotgun metagenomics, represented at phylum (A) and class (B) levels. Environmental

943 temperatures and geothermal sites of each sample are represented. Taxonomy assignments were

944 performed based on best hit classifications and M5NR (non-redundant protein database), with an

945 e-value of $<1 \times 10^{-5}$, minimum 50 bp alignment, and $60 \%$ identity. Co-occurrence network analysis

946 at the genus level are represented in (C), grouping triplicates of each sampling point and

947 highlighting the increases of environmental temperatures and complexity. Complexity was

948 calculated based on a set of measures, such as the number of nodes and edges, modularity, the

949 number of communities, average node connectivity, average path length, diameter, and cumulative

950 degree distribution.

952 Figure 3. Extended error plots for functional general profiles of microbial communities generated 953 through annotation of metagenomic reads, visualized through STAMP based on SEED 954 subsystems, are represented in (A). The $p$ values were calculated using Fisher's exact two-sided 955 test and the confidence intervals were calculated by the method from Newcombe-Wilson. 956 Differences were considered significant at $p<0.05$. PCA ordination was performed based on 957 functions at level 3 of the SEED subsystem (B). Heatmap is representing relative abundances of 958 level 1 functions (C). Samples are clustered and colored according to environmental temperature, 959 following the three different groups: $98{ }^{\circ} \mathrm{C}$ fumarole, $<80{ }^{\circ} \mathrm{C}$ fumaroles and glaciers. 
961 Figure 4. Extended error plots for functional profiles regarding metabolic pathways, including

962 sulfur, nitrogen and carbon metabolisms, and stress response, including oxidative and osmotic,

963 and heat/cold shock responses. Profiles were visualized through STAMP based on annotation of

964 metagenomic reads using SEED subsystems. The $p$ values are represented and were calculated

965 using Fisher's exact two-sided test, with the confidence intervals calculated by the method from

966 Newcombe-Wilson. Samples are clustered and colored according to environmental temperature,

967 following the three different groups: $98{ }^{\circ} \mathrm{C}$ fumaroles, $<80^{\circ} \mathrm{C}$ fumaroles and glaciers.

969 Figure 5. Spearman correlation between taxonomic profile (A) (phylum level) and functional 970 profile (level 1 SEED subsystem) (B) and environmental parameters. Only parameters that 971 exhibited $\mathrm{p}<0.05$ in a correlation analysis are represented. The environmental parameters are: 972 Temp (temperature), pH, EC (electrical conductivity), B, Cu, Fe, Zn, OM (organic matter), OC

973 (organic carbon), P, Si, Na, K, Ca, Mg, sulfate, nitrogen, ammonia, nitrate, sand, silt, and clay.

975 Figure 6. Functional annotation of the 11 selected metagenome-assembled genomes (MAGs), 976 including metabolic potential (A) and adaptive strategies (B). A black circle represents the 977 presence of genes or complete gene cluster/pathway, and a yellow circle represents incomplete 978 gene cluster or pathway. MAGs codes are represented on the upper side of figures, whereas their 979 taxonomic classification based on GTDB-Tk and GhostKoala are at the bottom. Genes are 980 presented here with identifiers of KEGG Orthology (KO), Clusters of Orthologous Groups (COG) 981 or Enzyme Commission numbers (EC).

983 Table legends

985 Table 1. List of the 11 selected MAGs and their taxonomic classification based on GTDB-Tk and 986 GhostKoala. Characteristics of total genome length, N50, GC content, redundancy and 987 completeness (based on CheckM), and the genome quality status, are described. 


\section{Supplementary Figures and Tables}

994 Figure S1. Relative abundances of microbial community taxonomy based on annotation of contigs,

995 represented at the phylum level. Contigs were constructed through IDBA-ud and annotated using

996 the Integrated Microbial Genomes \& Microbiomes (IMG/M) system.

Figure S2. Extended error plots for functional profiles regarding DNA repair, helicase and topoisomerase, protein biosynthesis, and transport and chemotaxis. Profiles were visualized through STAMP based on annotation of metagenomic reads using SEED subsystems. The $p$ values are represented and were calculated using Fisher's exact two-sided test, with the confidence intervals calculated by the method from Newcombe-Wilson. Samples are clustered and colored according to environmental temperature, following the three different groups: $98{ }^{\circ} \mathrm{C}$ fumarole, $<80$ ${ }^{\circ} \mathrm{C}$ fumaroles and glaciers.

Figure S3. A circular view of the 158 metagenome-assembled genomes (MAGs) that were recovered through anvi'o v. 5 pipeline and are represented with the mean coverage of contigs, and

1008 the MAGs redundancy, completeness, GC content, total reads mapped and number of SNVs 1009 reported. The clustering dendrogram in the center shows the hierarchical clustering of contigs 1010 based on their sequence composition, and their distribution across samples.

1011

1012 Figure S4. Heatmap representing the 13 high quality and 82 medium quality MAGs based on read 1013 mapping per sample with Z-score. Samples are clustered and colored according to environmental 1014 temperature, following the three different groups: $98{ }^{\circ} \mathrm{C}$ fumarole, $<80{ }^{\circ} \mathrm{C}$ fumaroles and glaciers.

1017 Table S1. Physical-chemical parameters data per sample including temperature, pH, EC (electrical 1018 conductivity), B, Cu, Fe, Zn, OM (organic matter), OC (organic carbon), P, Si, Na, K, Ca, Mg, 1019 sulfate, nitrogen, ammonia, nitrate, sand, silt, and clay.

1021 Table S2. General information about reads and contigs annotation. 
1023 Table S3. $P$-values of Spearman correlations comparing taxonomic and functional profiles with 1024 the environmental data.

1025

1026 Table S4. A complete list of all reconstructed MAGs with their characteristics: taxonomic 1027 classification based on GTDB-Tk and GhostKoala, the total genome length, N50, GC content, 1028 redundancy and completeness, based on anvi'o and CheckM, and the genome quality status. 
bioRxiv preprint doi: https://doi.org/10.1101/2020.08.07.241539; this version posted August 7, 2020. The copyright holder for this preprint (which was not certified by peer review) is the author/funder, who has granted bioRxiv a license to display the preprint in perpetuity. It is made available under aCC-BY-NC-ND 4.0 International license.

\section{FIGURE 1}

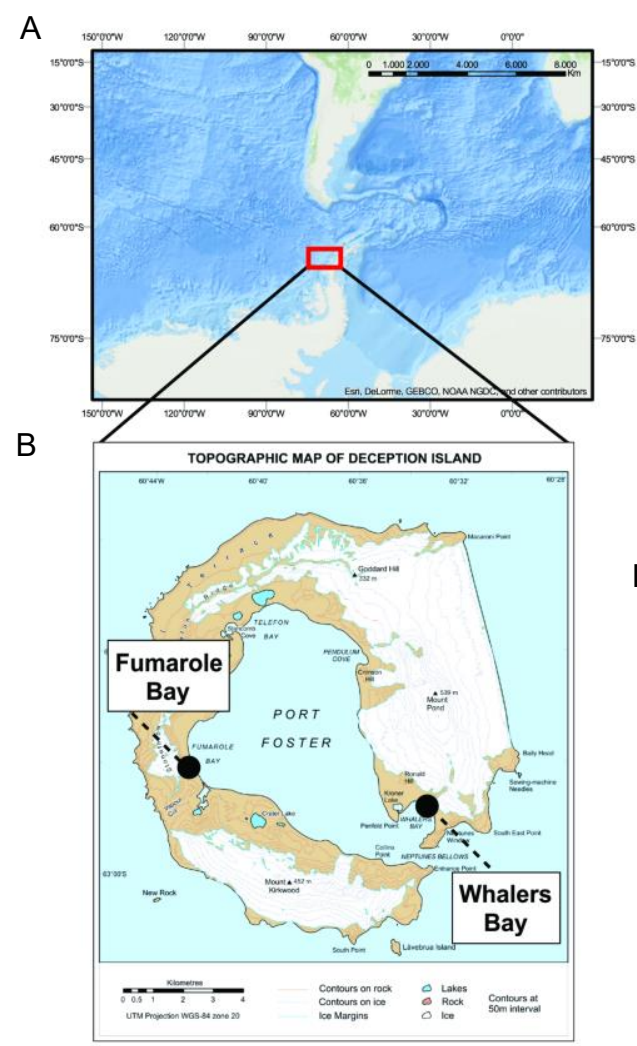

C

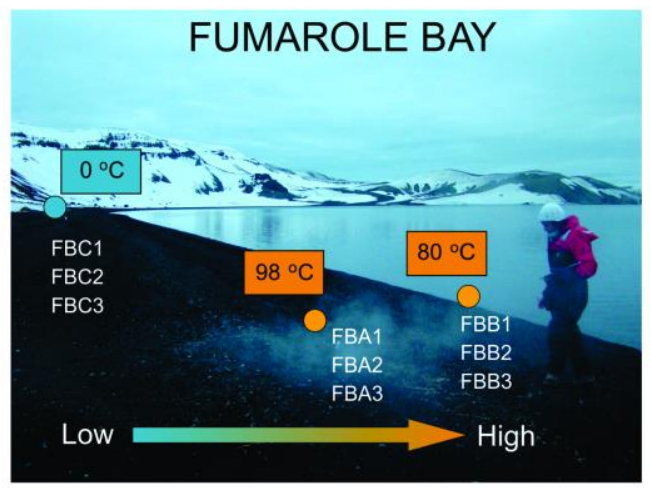

D

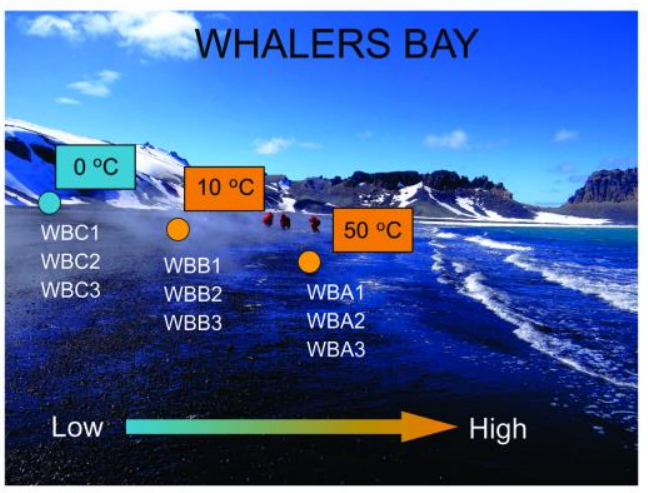


bioRxiv preprint doi: https://doi.org/10.1101/2020.08.07.241539; this version posted August 7, 2020. The copyright holder for this preprint (which was not certified by peer review) is the author/funder, who has granted bioRxiv a license to display the preprint in perpetuity. It is made available under aCC-BY-NC-ND 4.0 International license.

\section{FIGURE 2}
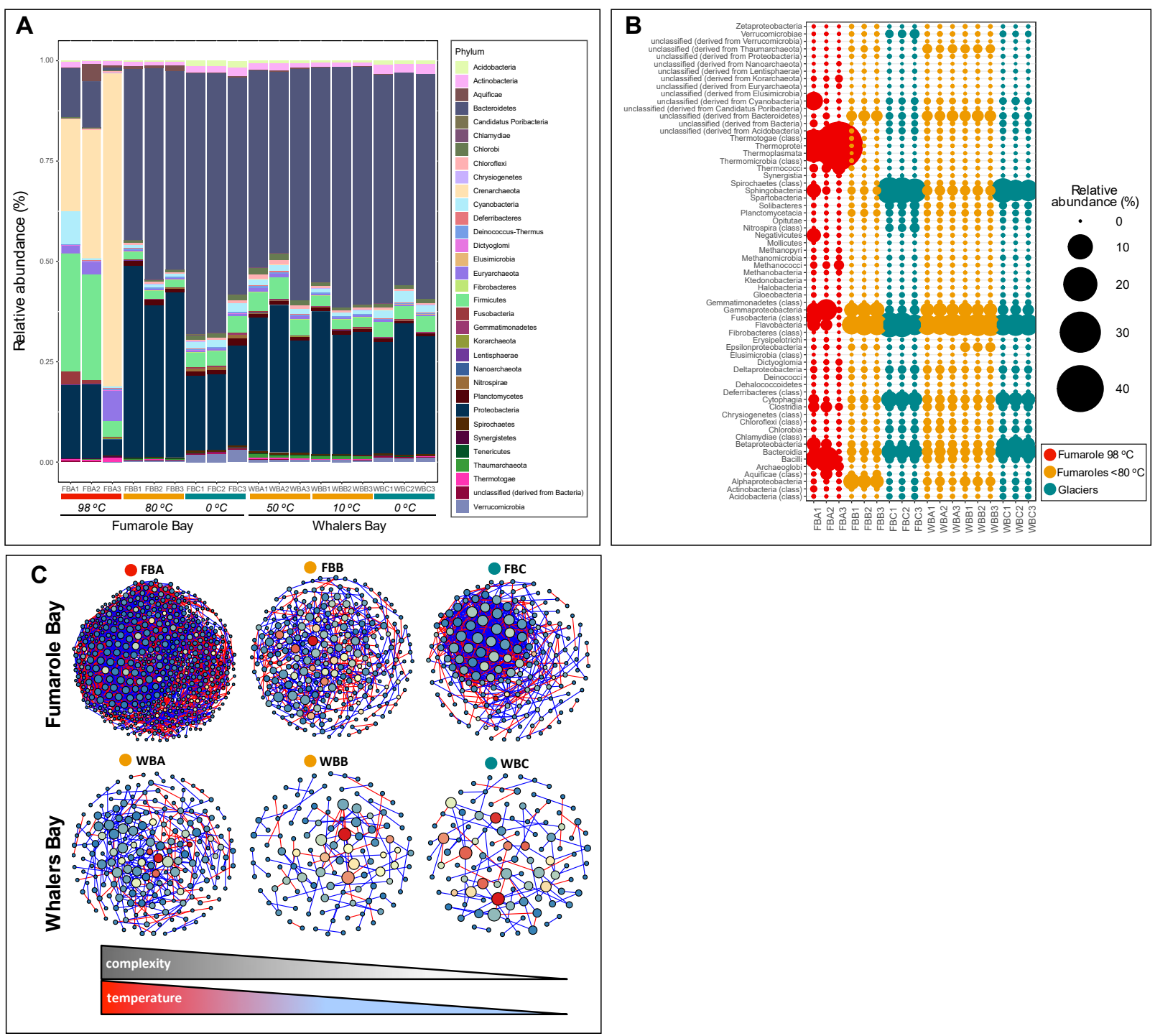
bioRxiv preprint doi: https://doi.org/10.1101/2020.08.07.241539; this version posted August 7, 2020. The copyright holder for this preprint (which was not certified by peer review) is the author/funder, who has granted bioRxiv a license to display the preprint in perpetuity. It is made available under aCC-BY-NC-ND 4.0 International license.

\section{FIGURE 3}

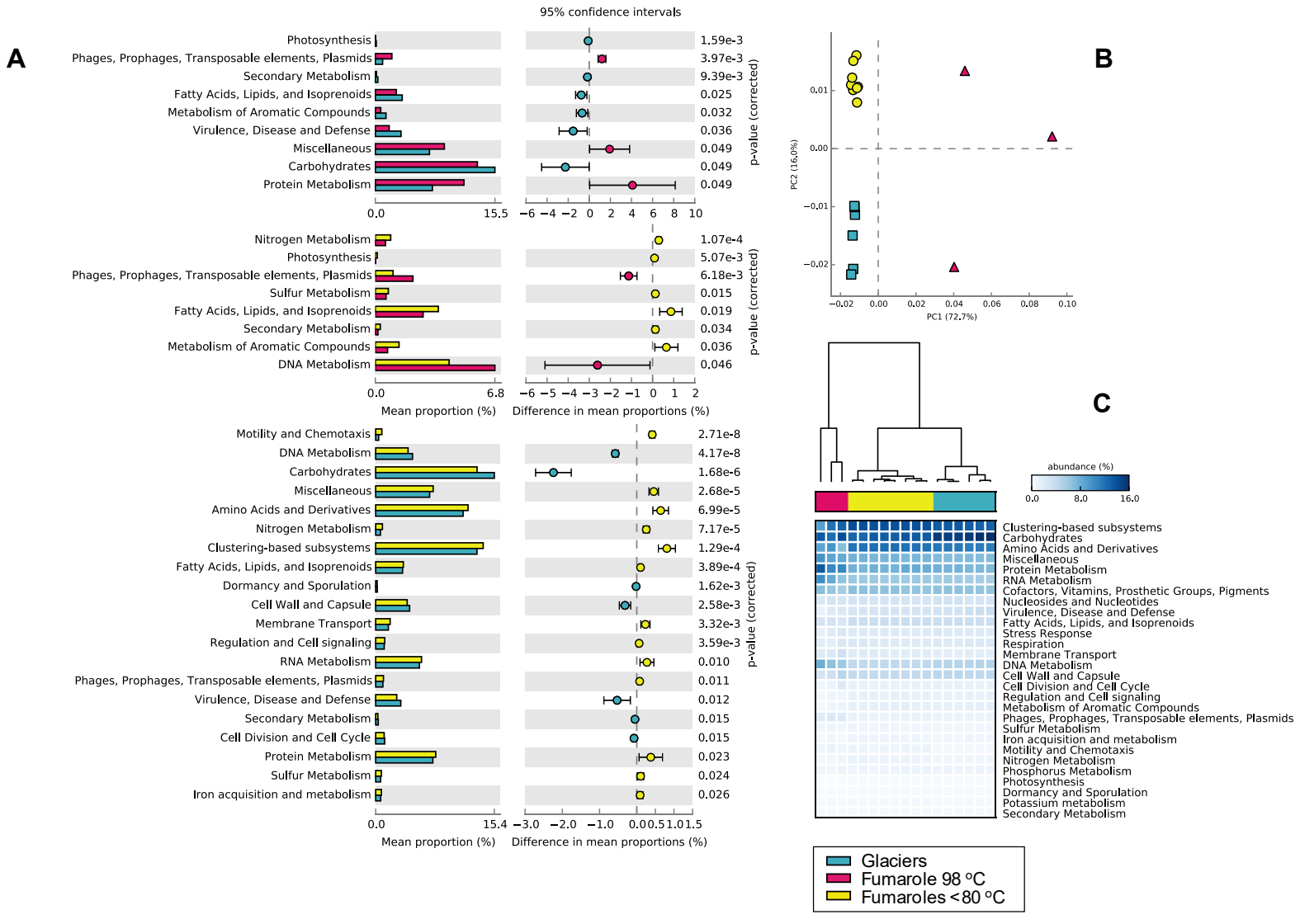


bioRxiv preprint doi: https://doi org/10.1101/2020.08 07 241539; this version posted August 7, 2020. The copyright holder for this preprint (which was not certified by peer review) is the author/funder, who has granted bioRxiv a license to display the preprint in perpetuity. It is made available under aCC-BY-NC-ND 4.0 International license.

\section{FIGURE 4}
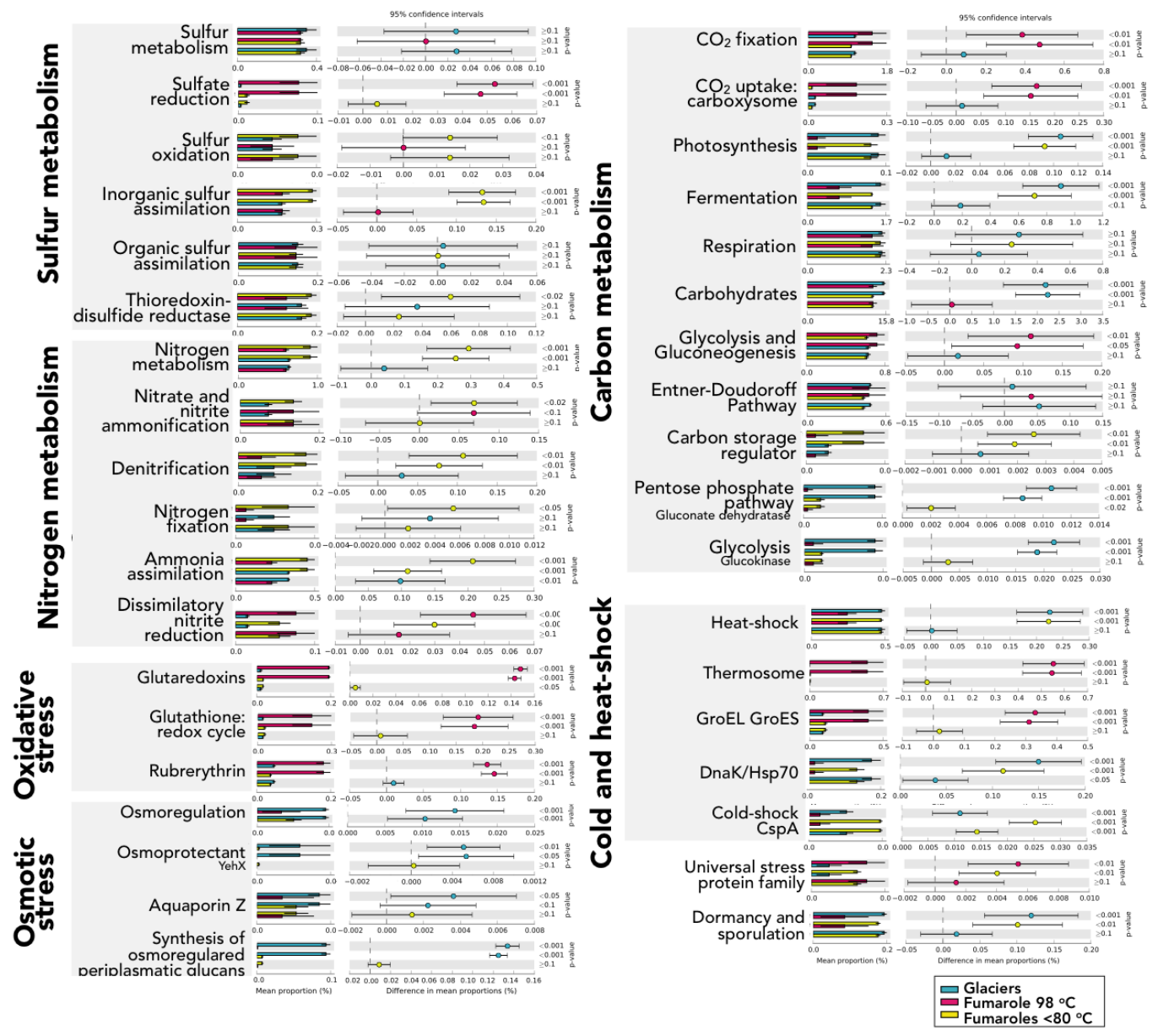
bioRxiv preprint doi: https://doi.org/10.1101/2020.08.07.241539; this version posted Auqust 7, 2020. The copyright holder for this preprint (which was not certified by peer review) is the author/funder, who has granted bioRxiv a license to display the preprint in perpetuity. It is made available under aCC-BY-NC-ND 4.0 International license.

\section{FIGURE 5}

A

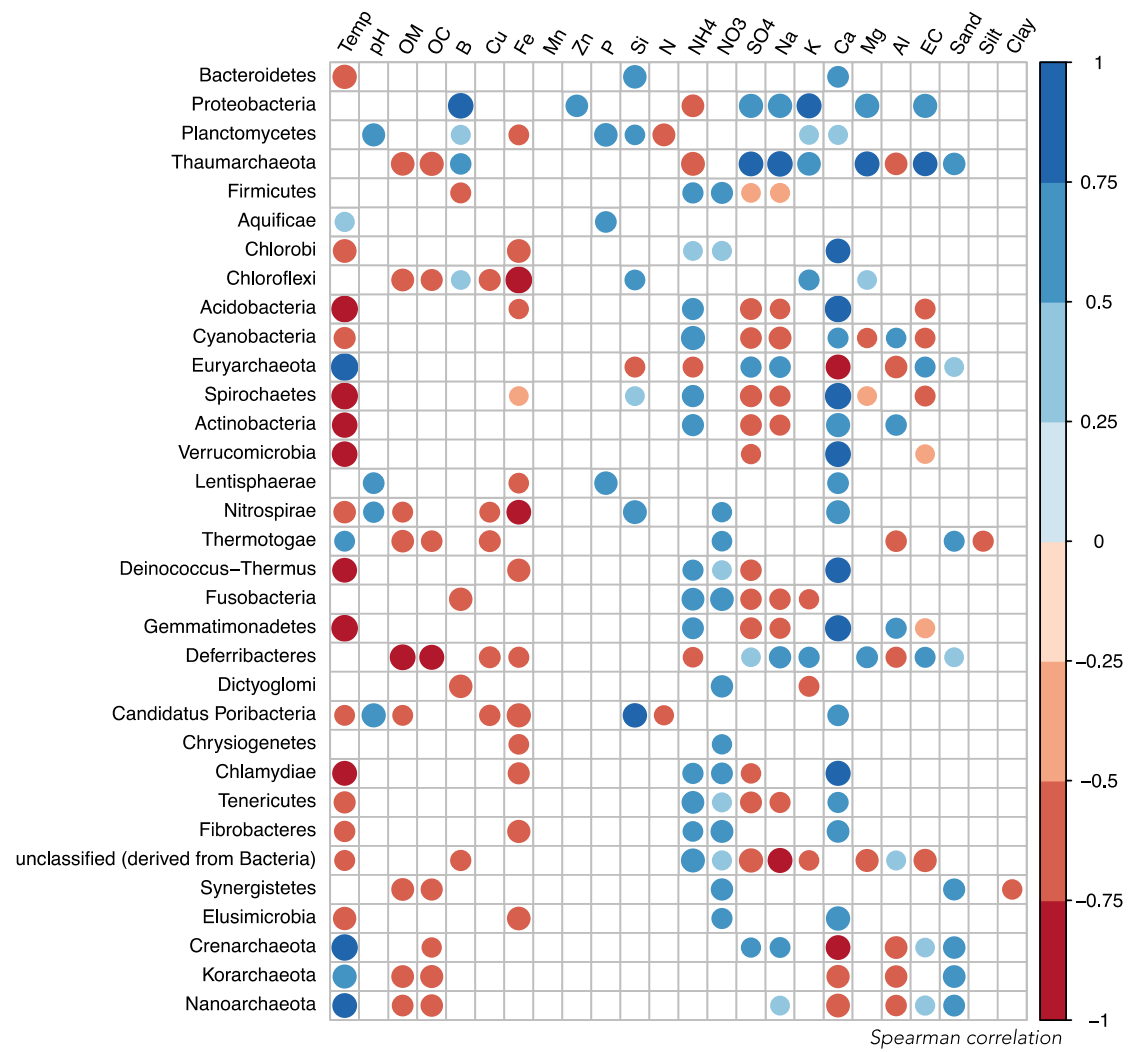

B

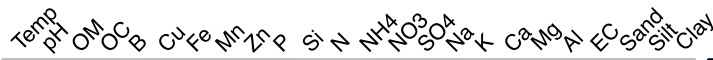

Amino Acids and Derivatives Carbohydrates Cell Division and Cell Cycle

Cell Wall and Capsule Clustering based subsystems Cofactors Vitamins Prosthetic Groups Pigments DNA Metabolism Dormancy and Sporulation Fatty Acids Lipids and Isoprenoids Iron acquisition and metabolism Membrane Transport Metabolism of Aromatic Compounds Miscellaneous Motility and Chemotaxis Nitrogen Metabolism Nucleosides and Nucleotides Phages Prophages Transposable elements Plasmids Phosphorus Metabolism Photosynthesis Potassium metabolism Protein Metabolism Regulation and Cell signaling Respiration RNA Metabolism econdary Metabolism Stress Response Sulfur Metabolism Virulence Disease and Defense

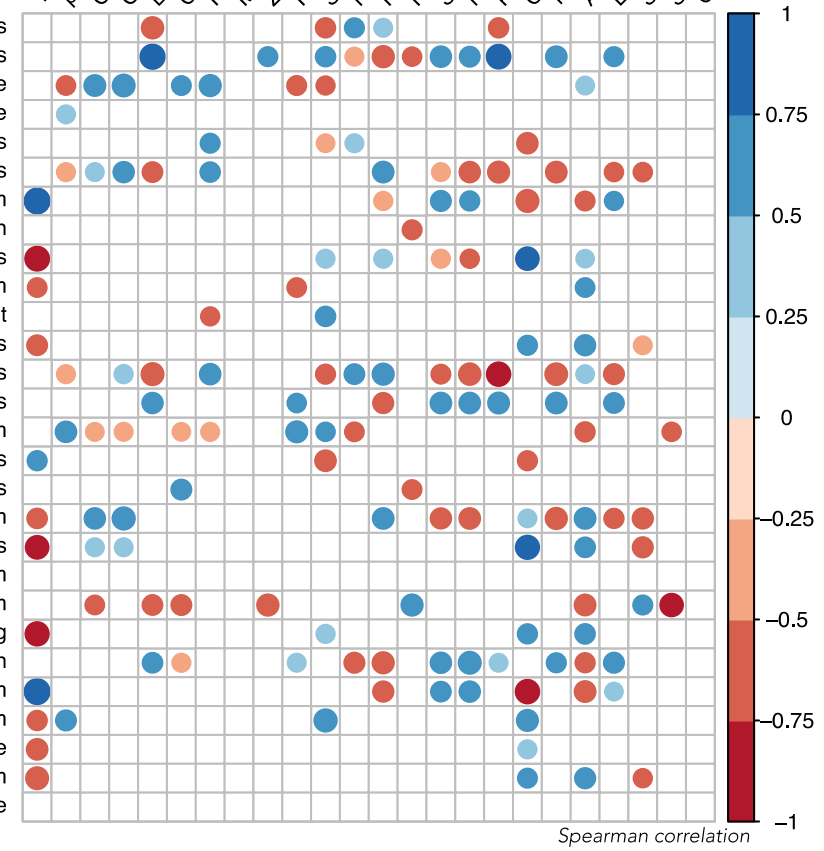


bioRxiv preprint doi: https://doi.org/10.1101/2020 08.07.241539; this version posted August 7. 2020. The copyright holder for this preprint (which was not certified by peer review) is the author/funder, who has granted bioRxiv a license to display the preprint in perpetuity. It is made available under aCC-BY-NC-ND 4.0 International license.

\section{FIGURE 6}

A

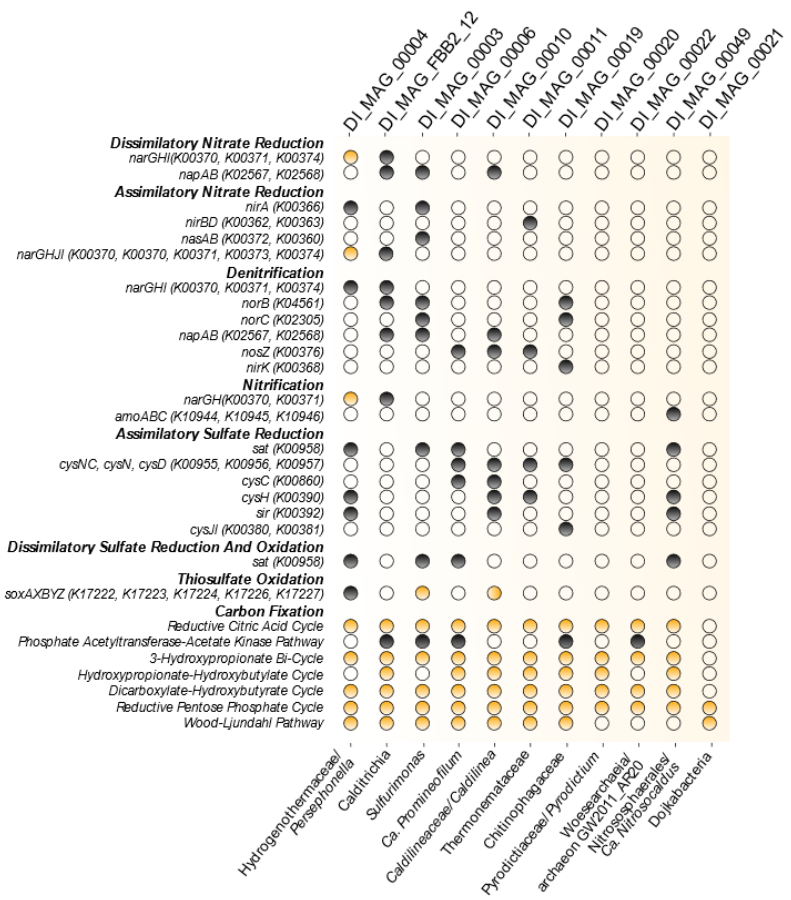

Presence of genes or complete gene cluster/pathway
B

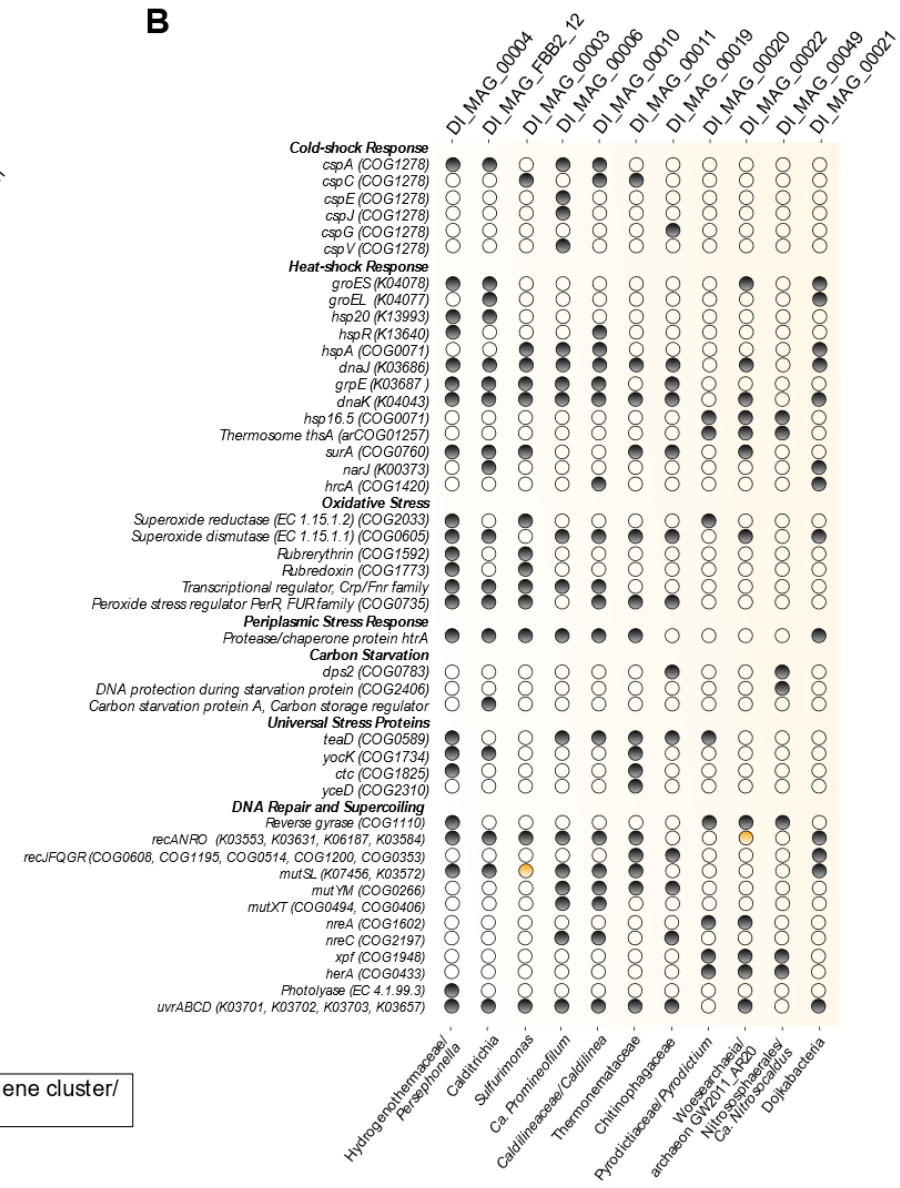


TABLE 1

\begin{tabular}{|c|c|c|c|c|c|c|c|c|c|}
\hline MAG Code & $\begin{array}{l}\text { KEGG/Ghost } \\
\text { Koala taxonomy }\end{array}$ & GTDB-Tk taxonomy & $\begin{array}{c}\text { Total } \\
\text { Length }\end{array}$ & $\begin{array}{l}\text { Contigs } \\
\text { number }\end{array}$ & N50 & $\begin{array}{c}\mathrm{GC} \\
\text { content }\end{array}$ & Completeness & Redundancy & $\begin{array}{c}\text { Draft } \\
\text { Quality }\end{array}$ \\
\hline DI_MAG_00003 & Sulfurimonas & $\begin{array}{l}\text { Bacteria; Campylobacterota; } \\
\text { Campylobacteria; } \\
\text { Campylobacterales; Thiovulaceae; } \\
\text { Sulfurimonas }\end{array}$ & $1,912,170$ & 94 & 32,276 & 39.42 & 97.95 & 0.41 & High \\
\hline DI_MAG_00004 & Persephonella & $\begin{array}{l}\text { Bacteria; Aquificota; Aquificae; } \\
\text { Hydrogenothermales; } \\
\text { Hydrogenothermaceae }\end{array}$ & $1,682,998$ & 67 & 44,923 & 30.32 & 98.37 & 0.22 & High \\
\hline DI_MAG_00006 & $\begin{array}{l}\text { Candidatus } \\
\text { Promineofilum }\end{array}$ & $\begin{array}{l}\text { Bacteria; Chloroflexota; } \\
\text { Anaerolineae; Promineofilales; } \\
\text { Promineofilaceae }\end{array}$ & $4,660,983$ & 56 & 102,288 & 52.27 & 92.73 & 2.00 & High \\
\hline DI_MAG_00010 & Caldilinea & $\begin{array}{l}\text { Bacteria; Chloroflexota; } \\
\text { Anaerolineae; Caldilineales; } \\
\text { Caldilineaceae }\end{array}$ & $4,473,267$ & 92 & 90,197 & 57.82 & 96.36 & 0.91 & High \\
\hline DI_MAG_00011 & Unknown & $\begin{array}{l}\text { Bacteria; Bacteroidota; Bacteroidia; } \\
\text { Cytophagales; Thermonemataceae }\end{array}$ & $2,518,210$ & 152 & 22,003 & 49.00 & 88.43 & 0.55 & High \\
\hline DI_MAG_00019 & Unknown & $\begin{array}{l}\text { Bacteria; Bacteroidota; Bacteroidia; } \\
\text { Chitinophagales; Chitinophagaceae }\end{array}$ & $3,082,789$ & 324 & 10,795 & 37.53 & 62.85 & 7.88 & Medium \\
\hline DI_MAG_00020 & Pyrodictium & $\begin{array}{l}\text { Archaea; Crenarchaeota; } \\
\text { Thermoprotei; Desulfurococcales; } \\
\text { Pyrodictiaceae }\end{array}$ & $1,071,537$ & 28 & 68,816 & 47.76 & 75.27 & 0.47 & Medium \\
\hline DI_MAG_00021 & Unknown & $\begin{array}{l}\text { Bacteria; Patescibacteria; } \\
\text { Dojkabacteria }\end{array}$ & 734,971 & 8 & 176,471 & 31.53 & 77.27 & 1.72 & Medium \\
\hline DI_MAG_00022 & $\begin{array}{l}\text { archaeon } \\
\text { GW2011_AR20 }\end{array}$ & $\begin{array}{l}\text { Archaea; Nanoarchaeota; } \\
\text { Woesearchaeia }\end{array}$ & $1,155,662$ & 40 & 83,443 & 44.63 & 79.44 & 0.00 & Medium \\
\hline DI_MAG_00049 & $\begin{array}{l}\text { Candidatus } \\
\text { Nitrosocaldus }\end{array}$ & $\begin{array}{l}\text { Archaea; Crenarchaeota; } \\
\text { Nitrososphaeria; Nitrososphaerales }\end{array}$ & 982,006 & 145 & 6,877 & 32.09 & 60.52 & 1.94 & Medium \\
\hline DI_MAG_FBB2_12 & Caldithrix & Bacteria; Calditrichota; Calditrichia & $2,931,548$ & 176 & 21,244 & 39.10 & 95.54 & 0.00 & High \\
\hline
\end{tabular}

